\title{
Melter Performance During Surrogate Vitrification Campaigns at the DOE/Industrial Center for Vitrification Research at Clemson University (U)
}

by

J. C. Marra

Westinghouse Savannah River Company

Savannah River Site

Aiken, South Carolina 29808

T. J. Overcamp

This paper was prepared in connection with work done under the above contract number with the U.S.

Department of Energy. By acceptance of this paper, the publisher and/or recipient acknowledges the U.S. Government's right to retain a nonexclusive, royalty-free license in and to any copyright covering this paper, along with the right to reproduce and to authorize others to reproduce all or part of the copyrighted paper. 
$\therefore$

$\because$ 


\section{DISCLAIMER}

Portions of this document may be illegible in electronic image products. Images are produced from the best available original document. 

WSRC-TR-95-0412

Melter Performance During Surrogate Vitrification Campaigns at the DOE/Industrial Center for Vitrification Research at Clemson University - (U)

\author{
James C. Marra
}

Westinghouse Savannah River Company

Thomas J. Overcamp

Clemson University - Environmental Systems Engineering Department

Westinghouse Savannah River Company

Savannah River Technology Center

Aiken, SC 29802

$\frac{\text { Oemes C.Mres }}{\text { Author's Signature }}$
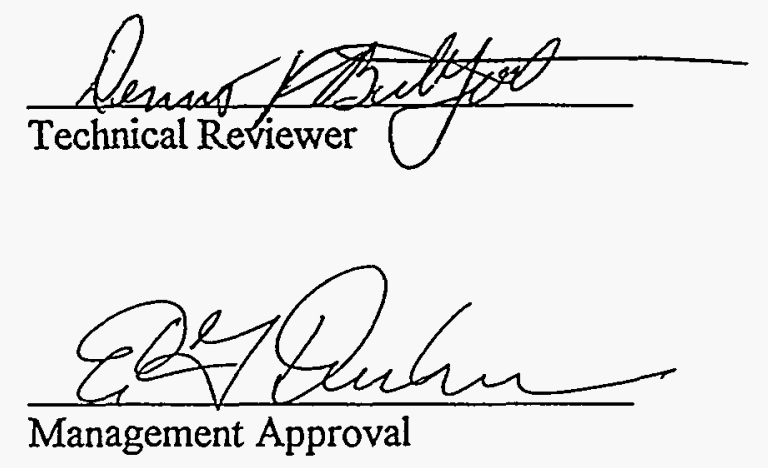


\section{DISCLATMER}

This report was prepared as an account of work sponsored by an agency of the United States Government. Neither the United States Government nor any agency thereof, nor any of their employees, makes any warranty, express or implied, or assumes any legal liability or responsibility for the accuracy, completeness, or usefulness of any information, apparatus, product, or process disclosed, or represents that its use would not infringe privately owned rights. Reference herein to any specific commercial product, process, or service by trade name, trademark, manufacturer, or otherwise does not necessarily constitute or imply its endorsement, recommendation, or favoring by the United States Government or any agency thereof. The views and opinions of authors expressed herein do not necessarily state or reflect those of the United States Government or any agency thereof.

This report has been reproduced directly from the best available copy.

Available to DOE and DOE contractors from the Office of Scientific and Technical Information, P.O. Box 62, Oak Ridge, TN 37831; prices available from (615) 576-8401.

Available to the public from the National Technical Information Service, U.S. Department of Commerce; 5285 Port Royal Road, Springfield, VA 22161. 


\section{Table of Contents}

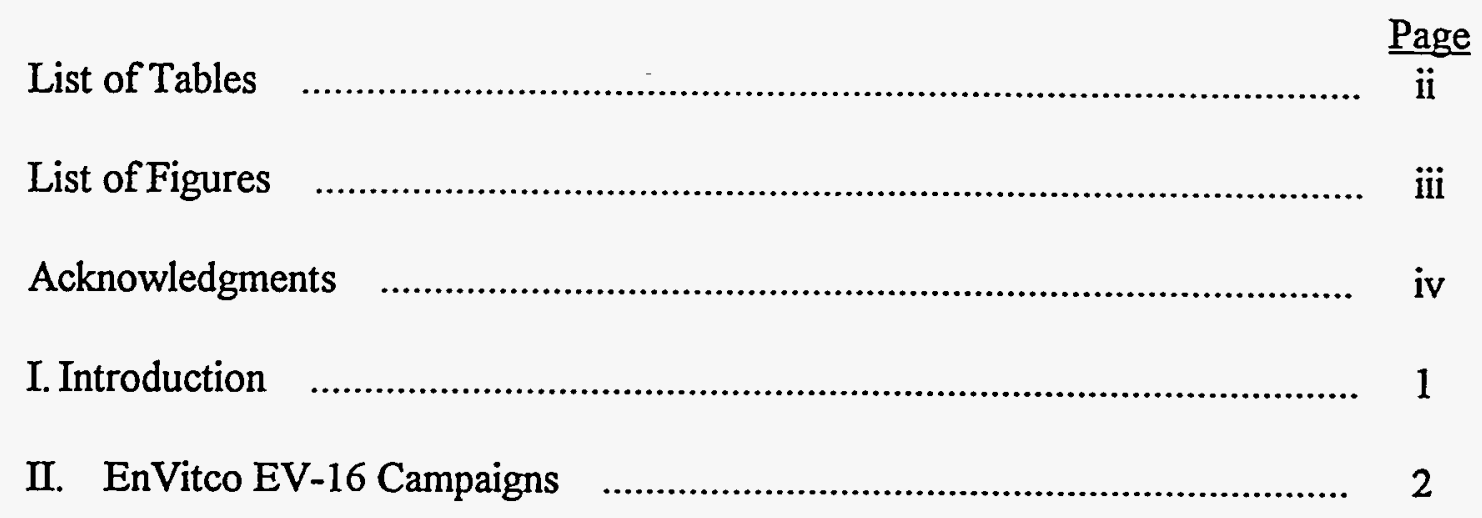

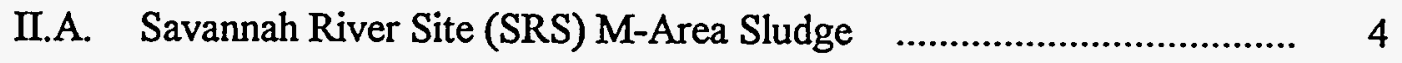

II.B. Oak Ridge Reservation Y-12

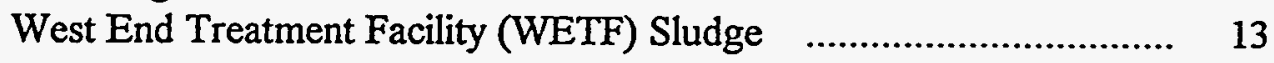

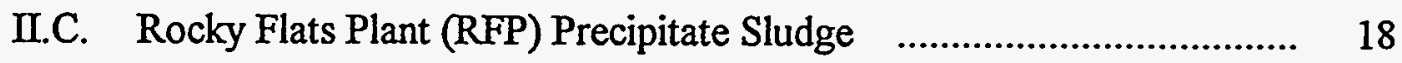

II.D. Lessons Learned $\quad$.................................................................... 24

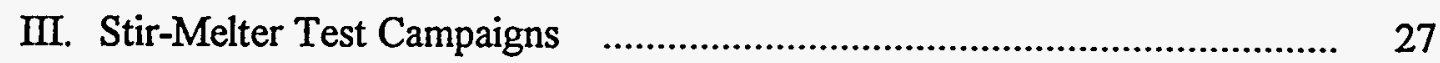

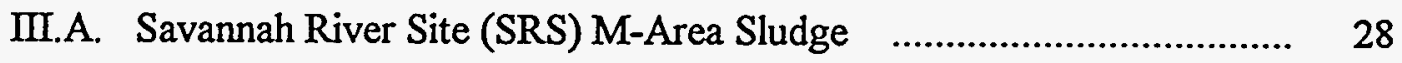

III.B. Oak Ridge Reservation Y-12

West End Treatment Facility (WETF) Sludge $\quad$................................ 33

III.C. Ion Exchange Resins $\quad$.......................................................... 38

III.D. Rocky Flats Plant (RFP) Precipitate Sludge $\quad$................................ 43

III.E. Lessons Learned $\quad$.................................................................... 46

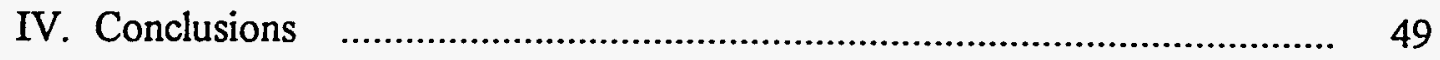

V. Current Activities $\quad$......................................................................... 50

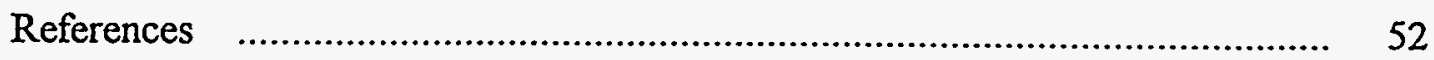




\section{List of Tables}

\section{Page}

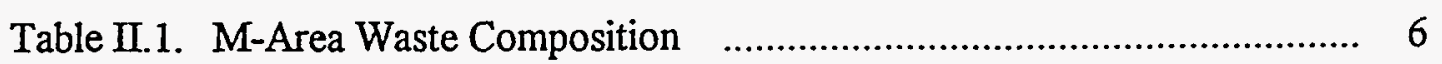

Table II.2. Waste and Surrogate Formulations ……….................................... 7

Table II.3. M-Area Batch Formulations ……………………........................... 9

Table II.4. Test Matrix and Operating Conditions - EnVitco Test Series $\quad$........... 10

Table II.5. Analyzed Batch Compositions vs. Final Glass Composition $\quad$............. 11

Table II.6. WETF Wastewater Sludge Simulant Compositions in Mass Percent ... 14

Table II.7. WETF Glass Compositions Expressed in Mass Percent $\quad \ldots \ldots \ldots \ldots \ldots \ldots . . . . .17$

Table II.8. RFP Precipitate Surrogate Composition ……................................. 20

Table II.9. Envitco Melter Operation Summary …….................................... 25

Table II. 1. M-Area Batch Formulations $\quad$......................................................... 30

Table III.2. Test Matrix and Operating Conditions - Stir-Melter Series $\quad \ldots \ldots \ldots \ldots . . . . .31$

Table III.3. Analyzed Batch Compositions vs. Final Glass Composition $\quad$............. 32

Table III.4. Operating Parameters For WV-0.25 ........................................... 35

Table III.5. Basic Matrix for Crucible Study Experiments .................................. 39

Table III.6. Stir-Melter Final Operating Conditions ……................................... 40

Table III.7. Analysis of Exit Glass Samples Taken at Different Times .............. 42

Table II.8. Stir-Melter Operation Summary $\quad$..................................................... 47 


\section{List of Figures}

\section{Page}

Figure II.1. Simplified Drawing of EnVitco EV-16 showing dry and slurry feed systems. The melter is illustrated without its metal drain

Figure III.1. Schematic of the WV-0.25 Stir-Melter with the Inconel ${ }^{\mathrm{TM}}$ vessel $\ldots . .27$ 
WSRC-TR-95-0412

\section{Acknowledgments}

A number of graduate students in the Environmental Systems Engineering Department at Clemson University were instrumental in the completion of this work. David Bennert conducted the vitrification efforts on surrogate $\mathrm{M}$-Area sludge. Thomas Sargent performed the work on the vitrification of ion-exchange resins. Kenneth Hewlett completed the testing on Oak Ridge Reservation West End Treatment Facility (WETF) surrogate sludge. Robert Wilson is currently completing efforts on the vitrification of Rocky Flats Plant Precipitate surrogate sludge.

The vitrification campaigns at the DOE/Industrial Center for Vitrification Research were completed under the direction of Dennis Bickford and Connie Cicero of the Savannah River Technology Center. 
WESTINGHOUSE SAVANNAH RIVER CO.

SAVANNAH RIVER TECHNOLOGY CENTER

WSRC-TR-95-0412

Keywords: Mixed Waste Focus Area (MWFA), Glass, Joule Heated Glass

Melters, Low-level Mixed Waste, Hazardous Waste, Sludge, Ion Exchange Resin

\title{
Melter Performance During Surrogate Vitrification Campaigns at the \\ DOE/Industrial Center for Vitrification Research at Clemson University - (U)
}

\author{
James C. Marra \\ Westinghouse Savannah River Company \\ Thomas J. Overcamp \\ Clemson University - Environmental Systems Engineering Department
}

\section{Introduction}

This report summarizes the results from seven melter campaigns performed at the DOE/Industrial Center for Vitrification Research at Clemson University. A brief description of the EnVitco EV-16 Joule heated glass melter and the Stir-Melter WV-0.25 stirred melter are included for reference. The report discusses each waste stream examined, glass formulations developed and utilized, specifics relating to melter operation and a synopsis of the results from the campaigns. Specific problems for each campaign are identified and discussed. A "lessons learned" section is included for each melter to emphasize repeated processing problems and identify parameters which are considered extremely important to successful melter operation.

Although the campaigns were designed to demonstrate large-scale operation, it must be noted that the runs were experimental in nature. The melters used were first-of-a-kind systems designed as prototypes for radioactive waste vitrification. As expected, several design modifications and augmentations were needed and system changes were made over the period of operation. Additionally, learning the intricacies of operating the melters was an integral part of the vitrification testing. Some of the processing problems are likely attributable to the "newness" of operating the melters.

This report primarily chronicles the results from the vitrification campaigns specifically related to melter operation. A significant amount of off-gas testing was performed during the testing. In an attempt to focus on the operation of the melters, little of the off-gas data is discussed in detail in this report. Data from the off-gas testing is included, however, when it was thought to assist in the overall description of the test results. 
WSRC-TR-95-0412

September 29, 1995

Page 2 of 53

\section{EnVitco EV-16 Melter Campaigns}

EV-16 Melter: The EV-16 melter is a refractory-lined, Joule-heated melter. It is classified as a high-temperature melter due to its ability to process at temperatures in excess of $1300^{\circ} \mathrm{C}$. A drawing of the melter is seen in Figure II.1. The electrodes are four molybdenum rods below the glass level, one electrode on each face of the melter. The melter power supply is rated for a maximum of $100 \mathrm{~kW}$ using $240 \mathrm{~V}$ and $500 \mathrm{~A}$. Mixing in the melter is caused by convection due to thermal gradients near the electrodes.

The melter was originally equipped with a $45.7 \mathrm{~cm}\left(18^{\prime \prime}\right)$ cube-shaped melt chamber with a slanted bottom extension giving a potential to recover molten metals. There was a separate drain for the recovery of metals. Later, the slanted bottom was replaced by a thick refractory bottom block and the metals drain was removed. The four walls of the melt chamber are lined with refractory. During the past two and one-half years, a variety of refractory materials have been used including low duty fire clay (flux block), aluminazirconia-silicate (AZS), and high chrome refractories. The bottom has always been constructed of fire clay refractory.

The melter is surrounded by water-cooled panels that provided a safe, cool exterior for the melter. The system was originally designed for once-through cooling. Clemson University has added closed-loop cooling with the melter cooling water-cooled in a heat exchanger. The heat is transferred to water, which is cooled in a small evaporative water-cooling tower.

The drain for the EV-16 is a molybdenum tube in the center of the bottom block. The glass flows through an orifice in this tube and falls as a continuous stream into a crucible positioned below the melter. The flow of glass is controlled by a water-cooled, steel probe that can seal the drain orifice and solidify glass in the orifice or a molybdenumtipped, water-cooled steel probe that mechanically seals the drain.

The hood supplied with the melter is stainless steel and is lined with refractory board. The hood has a large swing-open door with two smaller windows that individually open. Since the melter does not have any supplemental heating, such as electric or gas-fired heaters in the hood for start-up, the melter is started manually. Glass cullet is put into the melter until it is slightly above the electrodes. The region between the electrodes is mined out and filled with ground glass cullet and soda ash. The power supply is turned on and a hand-held torch is used to melt the glass between the electrodes and initiate the current flow. When there is current flow in both zones, the torch is removed and additional cullet is placed in the melter. When the melter appears to be completely melted, the feed can be started. 
The melter can be operated in either a hot-top or a cold-top mode. Dry feed can be distributed on the surface to produce a cold cap of feed materials. Slurry feed can be distributed on the surface of the molten glass to produce a layer of boiling and drying slurry. Either layer conserves heat by blocking high radiative losses and providing an insulating layer. These layers serve to decrease emissions of volatile components through condensation and recycle to the melt. With hot-top operation, offgas temperatures of $500-600^{\circ} \mathrm{C}$ have been measured. With a cold cap using dry feeds, the offgas temperatures are usually below $100^{\circ} \mathrm{C}$.

With slurry feed, $2.5 \mathrm{~cm}$ thick aluminosilicate fiber refractory boards are often placed on the top of the refractory walls to decrease radiative heat transfer to the headspace. This typically lowers the headspace temperatures above these boards to $200^{\circ}$ to $400^{\circ} \mathrm{C}$ under normal operating conditions.

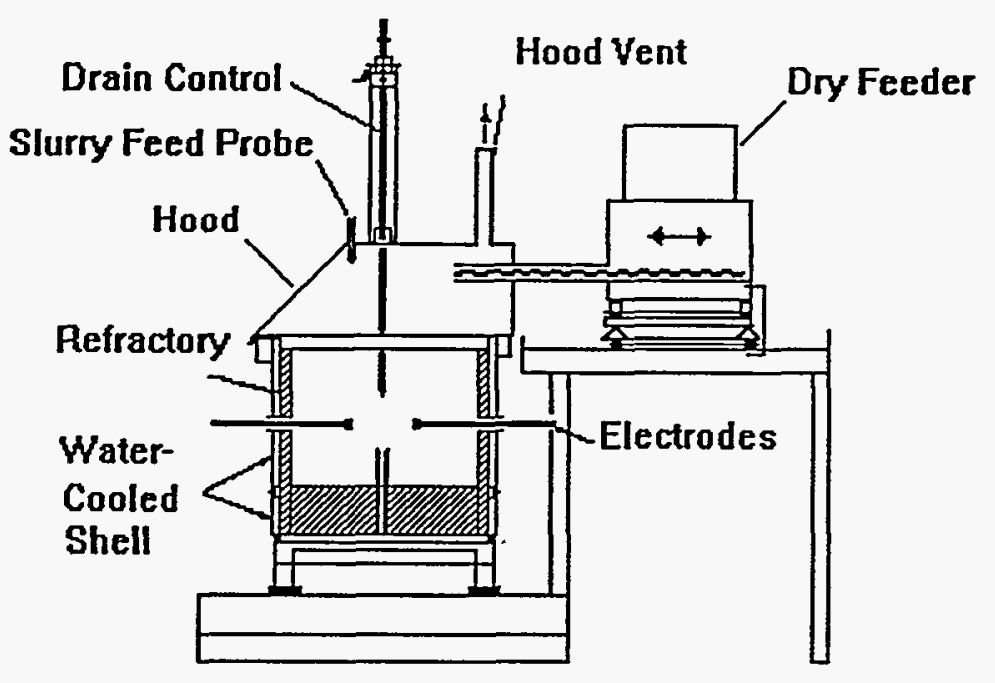

Figure II.1. Simplified Drawing of the EnVitco EV-16 showing the dry and slurry feed systems. The melter is illustrated without its metal drain.

Feed Systems: The EnVitco melter was supplied with an AccuRate feeder consisting of an open hopper and auger feeder as shown in Figure II.1. This feeder must be moved manually to distribute the feed material across the top of melt surface.

A slurry feed system was added by Clemson University. Slurry is mixed in a large agitated tank. Currently tanks of approximately 100,280 , and 700 gallons are available. The largest tank has water cooling coils to keep the slurry near ambient temperatures. Each tank has its own agitator with motor and motor drive. The slurry is continuously pumped 
by a Wilden diaphragm pump through a loop of $1 \frac{1}{2}$ " Schedule 10 stainless steel pipe to the melter and back to the tank. A small fraction of this slurry is directed through a tee near the melter feed port to either one or two Masterflex peristaltic pumps that meter sludge to the melter. The feed tube is a water-cooled 304 stainless steel tube approximately $60 \mathrm{~cm}$ (24") in length.

Offgas Treatment System: The offgas treatment system has been installed by Clemson University. This system has been continually upgraded to increase capabilities. Initially it was a dry system using a large fiberglass and sand deep-bed filter as the primary particulate control device. This was later supplemented with a water-spray quench, a cycionic separator to remove water droplets and large particles, and a mist eliminator. Currently, the offgas system has a 2" Schedule 10 stainless steel riser with a sampling port that is approximately $1 \mathrm{~m}$ from the melter. The gases are quenched in a stainless steel chamber. After exiting the quench chamber, the gases flow through a stainless steel pipe into a Lone Star steam atomizing scrubber. This scrubber is supplied with water for scrubbing and either compressed air or steam for atomization. The gases then flow into a cyclonic demister and a filter demister. The gases next flow through a counterflow, packed column that has the capability of neutralizing acid gases. Finally, the gases go through a positive-displacement, rotary blower and up the vent stack.

\section{II.A. Savannah River Site (SRS) M-Area Sludge}

\section{II.A.1. Test Objectives}

The objective of this test program was to demonstrate vitrification of surrogate M-Area sludge glass formulations in the EnVitco melter (Bennert, 1995). The conditions were varied by using various levels of added flux (sodium and boron as borax) to show the effects of changing waste loadings, melting temperatures, and glass characteristics. The process was evaluated based on general melter performance, processing rates, offgas characterization by EPA Method 5, glass leachability according to the Environmental Protection Agency (EPA) Toxicity Characteristic Leaching Procedure (TCLP) and the Product Consistency Test (PCT). The results from the testing pertaining to melter operation are summarized in this section. 
WSRC-TR-95-0412

September 29, 1995

Page 5 of 53

II.A.2. Waste Composition

M-Area sludge is a listed F006 ${ }^{2}$ non-specific source waste that was generated through the treatment of wastewaters from processes associated with the production of depleted uranium target assemblies for SRS plutonium-239 production. The slug production process included etching, cleaning, and nickel plating of uranium cores, drawing and forming of aluminum cladding, and autoclave pressure testing of completed core assemblies. The wastewater from the production processes, as well as the release of uranium that occurred from cladding failure during pressure testing, resulted in wastewaters containing uranium, nickel.and aluminum particles. Failed assemblies were stripped of the aluminum cladding and nickel plate using caustic and nitric acid etching processes, which further increased the concentration of nickel in the wastewater. The wastewater was transferred to the Liquid Effluent Treatment Facility (LETF), which consists of the Dilute Effluent Treatment Facility (DETF), Chemical Transfer Facility (CTF), and the Interim Treatment/Storage Facility (IT/SF). The dilute wastewater was received through the DETF, neutralized, then precipitated, flocculated and filtered through precoat pressure filters using diatomaceous earth or perlite filter aids.

The precipitate and spent filter aids were combined with the concentrated plating line residues and transferred through the CTF to the IT/SF, where it was accumulated and stored in three 500,000 gallon tanks, and six 35,000 tanks. A final pH adjustment was made to the liquid waste, increasing the $\mathrm{pH}$ to 12.5 to enhance the heavy metal precipitation in the IT/SF tanks. The composition of the waste in the tanks is presented in Table II.1.

\footnotetext{
${ }^{a}$ Industrial and EPA hazardous waste number F006: Wastewater treatment sludges from electroplating operations except from the following processes: (1) Sulfuric acid anodizing of aluminum; (2) tin plating on carbon steel; (3) zinc plating (segregated basis) on carbon steel; (4) aluminum or zinc-aluminum plating on carbon steel; (5) cleaning/stripping associated with tin, zinc and aluminum plating on carbon steel; and (6) chemical etching and milling on aluminum.
} 
WSRC-TR-95-0412

September 29, 1995

Page 6 of 53

Table II.1. M-Area Waste Compositiona

\begin{tabular}{cc}
\hline \hline Mass Balance Speciation & Weight \% \\
\hline $\mathrm{Al}(\mathrm{OH}) 3$ & 23.18 \\
$\mathrm{NaNO} 3$ & 17.88 \\
$\mathrm{SiO} 2$ & 43.44 \\
$\mathrm{Na6U7O24}$ & 3.48 \\
$\mathrm{Ca}$-zeolite & 3.15 \\
AlPO4 & 4.32 \\
Total & 95.45 \\
\hline
\end{tabular}

a WSRC Internal Memorandum, Jantzen, C.M., to Plodinec, M.J., Solidification of M-Area Sludge and Supernate into Low-Temperature Glass: I. Sludge and Supernate Characterization, March 1, 1989, Document DPST-89-351

Based on this composition, a surrogate waste formulation was developed (Jantzen, 1993). A comparison of the surrogate to the waste on an oxide basis is presented in Table II. 2 . Analysis of the actual waste reveals the presence of the a combination of oxides, hydroxides, nitrates, and calcium-sodium zeolite formations. The zeolite is believed to have resulted from reactions of $\mathrm{NaOH}$ with the perlite in the waste tanks. As shown in Table II.2, uranium and molybdenum were not included in the surrogate formulation. The omission of uranium was primarily due to restrictions on the use of radioactive materials in the test melters. Testing of $\mathrm{HLW}$ glasses has demonstrated that uranium leaching is no worse than other elements due to chemical bonding in the glass structure. Molybdenum was omitted from the surrogate formulation. Molybdenum, on the other hand, appears in low concentration in the waste and is not an LDR metal, therefore would not be expected to affect durability or leaching data. It is also the electrode material in the EnVitco melter, so it would be difficult to track for any mass balance information. Several anions were also excluded from the recipe. The decision not to use these components was based on the limitations of the offgas control system at the time of testing. The surrogate and glass batch were prepared and introduced to the melter in a dry form in these tests. 
Table II.2. Waste and Surrogate Formulations

\begin{tabular}{|c|c|c|}
\hline Oxide & M-Area Waste Composition & $\frac{\text { Simulated M-Area Composition }}{\text { wt \% }}$ \\
\hline $\mathrm{SiO}_{2}$ & 43.58 & 54.334 \\
\hline $\mathrm{Al}_{2} \mathrm{O}_{3}$ & 17.47 & 21.768 \\
\hline $\mathrm{B}_{2} \mathrm{O}_{3}$ & 0.03 & 0.040 \\
\hline $\mathrm{Na}_{2} \mathrm{O}$ & 10.83 & 13.513 \\
\hline $\mathrm{K}_{2} \mathrm{O}$ & 1.48 & 1.847 \\
\hline $\mathrm{MgO}$ & 0.20 & 0.248 \\
\hline $\mathrm{CaO}$ & 0.48 & 0.593 \\
\hline $\mathrm{BaO}$ & 0.02 & 0.035 \\
\hline $\mathrm{Cr}_{2} \mathrm{O}_{3}$ & 0.01 & 0.018 \\
\hline $\mathrm{CuO}$ & 0.03 & 0.031 \\
\hline $\mathrm{Fe}_{2} \mathrm{O}_{3}$ & 0.88 & 1.105 \\
\hline $\mathrm{MnO}$ & 0.28 & 0.354 \\
\hline $\mathrm{NiO}$ & 0.93 & 1.158 \\
\hline $\mathrm{PbO}$ & 0.11 & 0.134 \\
\hline $\mathrm{ZnO}$ & 0.59 & 0.729 \\
\hline $\mathrm{P}_{2} \mathrm{O}_{5}$ & 3.22 & 4.028 \\
\hline $\mathrm{TiO}_{2}$ & 0.04 & 0.062 \\
\hline $\mathrm{UO}_{2}$ & 3.00 & n.a. \\
\hline $\mathrm{MoO}_{3}$ & 0.01 & n.a. \\
\hline $\mathbf{F}$ & 0.03 & n.a. \\
\hline $\mathrm{Cl}$ & 0.26 & n.a. \\
\hline $\mathrm{SO}_{4}$ & 0.03 & n.a. \\
\hline $\mathrm{NO}_{3}$ & 13.05 & n.a. \\
\hline Total & 96.58 & 99.98 \\
\hline
\end{tabular}


WSRC-TR-95-0412

Page 8 of 53

September 29, 1995

\section{II.A.3. Glass Formulation}

Glass formulations were developed by SRTC (Jantzen, 1993). Tailoring the formulations to the waste and the melters required consideration for the melting point, viscosity, leach resistance, and waste loading. M-Area sludges are high in silica due to the existence of perlite and diatomaceous earth filter aids, both of which are primarily silica. The existence of high concentrations of silica made the waste ideal for vitrification, though adjustments were necessary to bring the formulation into the glass forming region of the $\mathrm{Na} 2 \mathrm{O}-\mathrm{CaO}$ $\mathrm{SiO}_{2}$ or $\mathrm{Na} 2 \mathrm{O}-\mathrm{B}_{2} \mathrm{O}_{3}-\mathrm{SiO}_{2}$ system.

Batch for the melters was prepared by the addition of borax $\left(\mathrm{Na}_{2} \mathrm{~B}_{4} \mathrm{O}_{7} \bullet 1 \mathrm{H}_{2} \mathrm{O}\right)$ to the simulant sludge. The borax contributed both sodium and boron to the glass matrix. The amount of borax addition was varied, to result in $30 \%, 20 \%, 10 \%$, and $5 \%$ added flux as $\mathrm{B}_{2} \mathrm{O}_{3}$ and $\mathrm{Na}_{2} \mathrm{O}$. The test plans called for testing three compositions $(20 \%, 10 \%$, and $5 \%$ flux) on each melter. Tests conducted with the $30 \%$ flux addition were not part of the test plan, but were conducted during startup trials. Characterization data from this run is not presented. The batch formulations are summarized in Table II.3.

\section{II.A.4. Melter Operation}

As part of the melter setup prior to testing, the electrodes were adjusted to approximately seven inches tip-to-tip. This was a typical setup based on recommendations from EnVitco personnel. The selection of seven inches allowed for a reasonably high energy and heat concentration in the center of the melter, driving convective mixing from the hotter center of the melt chamber. Electrode settings for subsequent tests were approximately the same (seven inches tip-to-tip), though accelerated wear of the electrodes resulted in higher tipto-tip settings as the test progressed. This is discussed later in section II.B.6. The feed was presented to the melter continuously through a $3^{\prime \prime}$ auger tube with a $2.5^{\prime \prime}$ auger. The feeder operated in a volumetric mode, and therefore was not compensating for changes in packing density of the material. The melter was operated in a cold-top mode, with two to six inches of feed on top of the molten glass bath at all times.

\section{II.A.5. Vitrification Process Challenges}

This was the first test campaign performed at the DOE/Industrial Center for Vitrification Research and several challenges in operating the melter were anticipated. Dry feeding of the batch was anticipated to present some problems due to the relatively fine particle size of some of the batch chemicals (i.e. perlite and precipitated silica). Additionally, the successful incorporation of some of the metals present in the surrogate waste, primarily nickel was considered a major goal of the study. 
WSRC-TR-95-0412

Page 9 of 53

September 29, 1995

Table II.3. M-Area Batch Formulations

\begin{tabular}{|c|c|c|c|c|}
\hline Material Additive & $\frac{\frac{30 \% \text { flux }}{\text { EnVitco }}}{\text { (M1) }}$ & $\frac{\frac{20 \% \text { flux }}{\text { EnVitco }}}{\frac{(\mathrm{M} 1-1)}{}}$ & $\frac{\frac{10 \% \text { flux }}{\text { EnVitco }}}{(\mathrm{M} 1-2)}$ & $\frac{5 \% \text { flux }}{\text { EnVitco }}$ \\
\hline Precipitated Silica (SiO2) & 13.17 & 16.21 & 19.73 & 21.72 \\
\hline Alumina $\left(\mathrm{Al}_{2} \mathrm{O}_{3} \cdot 3 \mathrm{H}_{2} \mathrm{O}\right)$ & 12.14 & 14.83 & 18.06 & 19.88 \\
\hline $\mathrm{B}_{2} \mathrm{O}_{3}$ & 0.02 & 0.02 & 0.03 & 0.03 \\
\hline $\mathrm{Na}_{2} \mathrm{CO}_{3}$ & 9.19 & 11.26 & 13.71 & 15.09 \\
\hline $\mathrm{KOH}$ & 0.02 & 0.03 & 0.03 & 0.03 \\
\hline $\mathrm{MgO}$ & 0.10 & 0.12 & 0.14 & 0.16 \\
\hline $\mathrm{Ca}(\mathrm{OH})_{2}$ & 0.21 & 0.26 & 0.32 & 0.35 \\
\hline $\mathrm{BaCO}_{3}$ & 0.01 & 0.02 & 0.02 & 0.02 \\
\hline $\mathrm{Cr}_{2} \mathrm{O}_{3}$ & 0.01 & 0.01 & 0.01 & 0.01 \\
\hline $\mathrm{CuO}$ & 0.01 & 0.01 & 0.02 & 0.02 \\
\hline $\mathrm{Fe}_{2} \mathrm{O}_{3}$ & 0.36 & 0.45 & 0.54 & 0.60 \\
\hline $\mathrm{MnO}$ & 0.10 & 0.18 & 0.21 & 0.24 \\
\hline $\mathrm{NiO}$ & 0.50 & 0.64 & 0.77 & 0.86 \\
\hline $\mathrm{PbCO}_{3}$ & 0.02 & 0.09 & 0.11 & 0.12 \\
\hline $\mathrm{ZnO}$ & 0.30 & 0.37 & 0.45 & 0.49 \\
\hline $\mathrm{Na}_{3} \mathrm{PO}_{4}$ & 4.22 & 5.22 & 6.35 & 6.99 \\
\hline $\mathrm{TiO}_{2}$ & 0.02 & 0.02 & 0.03 & 0.03 \\
\hline Perlite $^{a}$ & 14.76 & 18.13 & 22.07 & 24.29 \\
\hline Borax $^{b}$ & 44.72 & 32.14 & 17.39 & 9.07 \\
\hline Total & 99.88 & 100.01 & 99.99 & 100.00 \\
\hline
\end{tabular}

(a) Composition of Perlite as used: $77.40 \% \mathrm{SiO}_{2}, 12.79 \% \mathrm{Al}_{2} \mathrm{O} 3,5.14 \% \mathrm{~K}_{2} \mathrm{O}, 3.12 \% \mathrm{Na} 2 \mathrm{O}, 0.56 \%$ $\mathrm{CaO}, 0.45 \% \mathrm{Fe}_{2} \mathrm{O}_{3}, 0.17 \% \mathrm{MgO}$. Other constituents less than $0.01 \%$.

(b) Borax chemical formula $\left(\mathrm{Na}_{2} \mathrm{~B}_{4} \mathrm{O}_{7} \bullet 10 \mathrm{H}_{2} \mathrm{O}\right)$ 


\section{II.A.6. Vitrification Campaign Results}

The operating parameters for the three batch compositions processed in the EnVitco melter are summarized in Table II.4. These data were averages taken over the course of the demonstration, and do not include overnight or weekend "hot hold" periods.

Table II.4. Test Matrix and Operating Conditions--EnVitco Test Series

\begin{tabular}{cccccccc}
\hline \hline Test & Melter & $\frac{\text { Flux }}{(\%)}$ & $\frac{\text { Power }}{(\mathrm{kW})}$ & $\frac{\text { Voltage }}{(\mathrm{V})}$ & $\frac{\text { Pull Rate }}{(\mathrm{kg} / \mathrm{hr})}$ & $\frac{\text { Feed Rate }}{(\mathrm{kg} / \mathrm{hr})}$ & $\frac{\text { Glass Production }}{(\mathrm{kg})}$ \\
\hline & & & & & & & \\
M1-1 & EnVitco & 30 & 60 & 58 & 27.82 & 41.6 & 725 \\
M1-2 & EnVitco & 19 & 62 & 60 & N.D. & N.D. & 775 \\
M1-3 & EnVitco & 10 & 64 & 71 & 28.33 & 34.18 & 630 \\
\hline
\end{tabular}

(a) Actual flux levels presented, as related to tests M1-1 (20\%), M1-2 (10\%), and M1-3 (5\%).

N.D. $=$ not determined

Power utilization for the test series ran between 2.1 and $2.3 \mathrm{kWh} / \mathrm{kg}$ of glass produced. The energy input was consumed through the melting of the feed, evaporation of free water and water of hydration, and energy losses through the refractories to the water-cooled shell. Energy loss to the offgas was low, based on typical cold-top headspace temperatures of less than $50^{\circ} \mathrm{C}$. Energy loss to the water-cooled shell was variable, due to refractory wear that occurred over the course of the test. The refractory wall was 75 $\mathrm{mm}$ thick when installed, but wore to less than $20 \mathrm{~mm}$ thick in the area around the plane of the electrodes. This reduced the insulating capacity of the refractory, and contributed to additional energy loss to the water-cooled shell. No data are available to quantify the loss, though the impact is believed to be significant, since over $60 \%$ of the insulation was eroded from the hottest wall region in the melter.

The EnVitco melter was operated semi-continuously throughout the test program, with the melter producing for twelve hours, and on "hot hold" for twelve hours over a 30 day period. The melter setpoints presented are those for operating periods, with overnight or weekend "hot hold" conditions of $12 \mathrm{~kW}$ per zone, or about 24 total $\mathrm{kW}$. 
Prior to any sampling, it was verified that the melter had produced at least one volume of glass continuously without hot hold interruption. Once this was achieved, all sampling was completed without any interruptions.

The final glass compositions were generally in good agreement with target compositions (Table II.5.). Minor discrepancies due to analytical error in analyses of the batch may account for the differences.

Table II.5. Analyzed Batch Compositions vs. Final Glass Composition

\begin{tabular}{|c|c|c|c|c|c|c|}
\hline \multirow[b]{2}{*}{ Oxide } & \multicolumn{2}{|c|}{ EnVitco M1-1, 20\% Flux } & \multicolumn{2}{|c|}{ EnVitco M1-2, 10\% Flux } & \multicolumn{2}{|c|}{ EnVitco Ml-3, 5\% Flux } \\
\hline & $\frac{\text { Analyzed }}{\text { batch wt \% }}$ & $\frac{\text { Analyzed }}{\text { glass wt \% }}$ & $\underset{\text { batch wt \% }}{\text { Analyzed }}$ & $\begin{array}{l}\text { Analyzed } \\
\text { glass wt \% }\end{array}$ & $\begin{array}{l}\text { Analyzed } \\
\text { batch wt \% }\end{array}$ & $\frac{\text { Analyzed }}{\text { glass wt } \%}$ \\
\hline $\mathrm{Al}_{2} \mathrm{O}_{3}$ & 17.50 & 16.9 & 19.07 & 19.0 & 21.33 & 20.4 \\
\hline $\mathrm{B}_{2} \mathrm{O}_{3}$ & 17.14 & 16.7 & 8.88 & 8.5 & 4.47 & 4.46 \\
\hline $\mathrm{BaO}$ & 0.01 & 0.03 & 0.02 & 0.03 & 0.02 & 0.03 \\
\hline $\mathrm{CaO}$ & 0.54 & 0.43 & 0.54 & 0.59 & 0.59 & 0.62 \\
\hline $\mathrm{Cr}_{2} \mathrm{O}_{3}$ & 0.01 & 0.01 & 0.04 & 0.01 & 0.01 & 0.01 \\
\hline $\mathrm{CuO}$ & 0.00 & 0.02 & 0.00 & 0.02 & 0.00 & 0.02 \\
\hline $\mathrm{Fe}$ (total) & 0.68 & 0.78 & 1.34 & 0.92 & 0.97 & 0.99 \\
\hline $\mathrm{K}_{2} \mathrm{O}$ & $1.48^{\mathrm{a}}$ & 1.13 & $1.66^{\mathrm{a}}$ & 1.37 & $1.75^{\mathrm{a}}$ & 1.42 \\
\hline $\mathrm{MgO}$ & 0.19 & 0.21 & 0.20 & 0.24 & 0.20 & 0.25 \\
\hline $\mathrm{MnO}_{2}$ & 0.30 & 0.31 & 0.45 & 0.32 & 0.38 & 0.37 \\
\hline $\mathrm{Na}_{2} \mathrm{O}$ & 19.71 & 21.3 & 20.26 & 19.1 & 18.68 & 19.4 \\
\hline $\mathrm{NiO}$ & 0.83 & 0.75 & 0.99 & 0.81 & 1.00 & 0.86 \\
\hline $\mathrm{P}_{2} \mathrm{O}_{5}$ & 1.68 & 2.88 & 3.34 & 3.20 & 3.29 & 3.56 \\
\hline $\mathrm{PbO}$ & 0.03 & 0.11 & 0.05 & 0.12 & 0.03 & 0.14 \\
\hline $\mathrm{SiO}_{2}$ & 39.42 & 37.9 & 42.65 & 45.1 & 46.91 & 46.7 \\
\hline $\mathrm{TiO}_{2}$ & 0.02 & 0.07 & 0.03 & 0.08 & 0.03 & 0.07 \\
\hline $\mathrm{ZnO}$ & 0.53 & 0.45 & 0.61 & 0.55 & 0.65 & 0.58 \\
\hline Total & 100.07 & 99.98 & 100.13 & 99.96 & 100.31 & 99.88 \\
\hline
\end{tabular}

a Potassium analysis was not conducted by SRTC ADS. Results presented are normalized assuming K contribution at target values per each composition. 
The durability and leach resistance of the tested glasses were very good. The Product Consistency Test (PCT) results showed that the leaching of $\mathrm{Na}, \mathrm{B}$, and $\mathrm{Si}$ were all lower in the three glasses tested than in the Environmental Assessment (EA) glass. A significant difference was observed between glasses produced with $10 \%$ flux vs. $20 \%$ flux. A 5-10 fold decrease in elemental release was observed in the $10 \%$ flux glasses when compared to the $20 \%$ flux glasses. The release of the $5 \%$ flux glasses was similar to the $10 \%$ flux glasses. The Toxic Characteristic Leaching Procedure (TCLP) results were also promising. All elements except $\mathrm{Ni}$ and $\mathrm{Pb}$ were at or below the detection limit for the analytical system utilized. The $\mathrm{Ni}$ concentration in the leachate was below the LDR standards by at least $10 \%$ in the three glasses. The $\mathrm{Pb}$ concentration in the leachate was above detection limits on M1-2, 10\% flux glass, though still less than $40 \%$ of the LDR leachate concentration, and less than $4 \%$ of the characteristic waste leachate concentration. The high concentration for this particular sample may be due to analytical error or sampling error, since all of the other glass samples. $M 1-1, M 1-3, M 2-1$, and M22) yielded $\mathrm{Pb}$ leachate concentrations below detection limits.

A few processing problems were encountered during this test campaign. Since this was the first test campaign run at the DOE Industrial Center for Vitrification Research some of the problems may be attributed to the "newness" of operating the melter. Other problems, however, are worthy of mention since they were definitely related to the processing of this waste stream.

The batch depth varied significantly during the run, due to difficulties in locating the actual molten glass surface beneath the batch blanket. This in turn resulted in fluctuation in the melt level in the tank, causing variation in the melter operation. Melt depth changes affected the molten glass temperature at the glass-batch interface, and the temperature of the bulk glass/exit glass stream. It is difficult to determine the impact of these changes on the overall melter performance, though it is known that the bulk glass temperatures increased with decreases in the glass depth. When the glass level over the electrodes was lowered, the working volume was also lowered, and the same power input applied. The applied energy per unit of glass was higher, due to the decreased glass volume at the same power input, and the lower heat loss through lower glass/refractory contact area. As a result, the bulk glass temperature increased, and hence melting rate increased. The negative affects of these changes include increased wear on refractories due to higher temperatures and lower viscosities, and increased wear on molybdenum electrodes due to high-temperature alloying effects.

A major problem associated with these tests was due to the use of dry feed and its impact on the offgas/offgas treatment system. The dry feed caused problems with the offgas sampling, since the samples were almost exclusively made up of raw feed. Some of the 
initial EPA method 5 sampling runs yielded a cyclonic separator and filter housing completely filled with the feed that was being carried over from the melter to the offgas system. This was in part attributable to the species selected for the feed (carbonates, hydrates), and the decision to test dry feed versus slurry feed. The use of non-calcined species, with the major fraction of the particles in the 20-50 $\mu \mathrm{m}$ range resulted in a fluidized bed of easily entrained material. The theoretical release of carbon dioxide and water vapor from $5 \%$ and $20 \%$ flux feeds ranged from $18-29 \%$ of the mass feed rate, accounting for as much as $12 \mathrm{~kg} / \mathrm{hr}$ of carbon dioxide and water vapor. The release of gas from the feed, and the amount of air in-leakage into the plenum resulted in excessive carryover of unmelted feed to the offgas system. This was further compounded by condensation of the water vapor in the exiting offgas line, causing clogging at the connection between the offgas system and the melter plenum. These buildups required cleaning several times during the test in order to maintain a negative plenum pressure in the melter. In addition, the rapid deposition of feed material in the main filter caused a steady loss of flow capacity over the period of the test. The solids buildup and residual condensation typically blinded the filter within about $24-48$ operating hours.

The final test sequence ( $5 \%$ flux) pushed the limit of the melter, impacting the durability of the refractory and molybdenum electrodes (Bennert, 1994). This was likely due to an effort to accelerate the testing which caused higher localized heating around the electrodes and refractory walls. The electrodes deteriorated due to nickel (present in the waste glass) alloying with the molybdenum at these elevated temperatures. As the attack progressed, the electrodes continued to erode and become shorter, and carried higher current densities, which resulted in higher temperatures at the electrodes and the melter walls. This led to substantial deterioration of the melter walls in the plane of the electrodes. Approximately $60-70 \%$ of the wall thickness in the regions around the electrodes was lost due to corrosion/erosion at these elevated temperatures. Although severe attack was caused to the refractory walls, it was determined that the water-cooled shell provided enough cooling to prevent breaching of the refractory walls.

\section{II.B. Oak Ridge Reservation Y-12 West End Treatment Facility (WETF) Sludge}

\section{II.B.1. Test Objectives}

The principal objectives of this melter campaign were to demonstrate feasibility of vitrifying WETF waste sludge in a continuously operating Joule heated melter and to characterize the environmental impact on the vitrification process (Hewlett, 1994). The test program was aimed at obtaining information relating to: product quality, off-gas emissions characterization, material balances, and melter behavior and performance. A summary of the data relating to melter operation from this study is provided below. 


\section{II.B.2. Waste Composition}

The West End Treatment Facility is a liquid-waste treatment plant that generates sludge from biodenitrification and precipitation processes. The plant currently has an inventory of approximately $7,000 \mathrm{~m}^{3}$ (Jantzen, 1995). The WETF treatment process consists of a biodenitrification step and heavy-metal precipitation using hydrated lime. The sludge resulting from the process is stored in epoxy-coated, steel tanks located in the West Tank Farm (WTF). Approximately $90 \%$ of the sludge consists of calcium carbonate and . biomass generated from the biological denitrification of the wastewater. The balance, generated in a lime treatment process, contains heavy metal hydroxides. Uranium is the primary radionuclide in the sludge with smaller amounts of neptunium, technetium, and thorium. The sludge also contains nickel, chromium, lead, and a low concentration of organic compounds. From a hazardous waste regulatory perspective, Oak Ridge Reservation has classified this sludge as a F006 waste from the treatment of plating wastes and as a F001, F002, and F005 waste from the treatment of solvent residues (Jantzen, 1995). A surrogate waste formulation was developed and is listed in Table II.6. (Jantzen, 1995).

Table II.6. WETF Wastewater Sludge Simulant Compositions in Mass Percent.

\begin{tabular}{lcll}
\hline \hline Element & Mass Percent & Component & Mass Percent \\
\hline $\mathrm{Al}$ & 4.5 & Dried Yeast & 6.27 \\
$\mathrm{Ba}$ & 0.06 & Dodecane & 1.5 \\
$\mathrm{Ca}$ & 27.00 & Phenol & 0.02 \\
$\mathrm{Cd}$ & 0.005 & & \\
$\mathrm{Cl}$ & 0.068 & & \\
$\mathrm{Cr}$ & 0.047 & & \\
$\mathrm{Cu}$ & 0.127 & & \\
$\mathrm{Fe}$ & 1.43 & & \\
$\mathrm{Mg}$ & 0.94 & & \\
$\mathrm{Na}$ & 2.10 & & \\
$\mathrm{Ni}$ & 0.13 & & \\
$\mathrm{~Pb}$ & 0.028 & & \\
$\mathrm{P}$ & 0.30 & & \\
\hline \hline
\end{tabular}




\section{II.B.3. Glass Formulation}

Due to the high calcium content in the waste, a relatively high temperature calcium aluminosilicate $(\mathrm{CAS})$ glass formulation (melting temperature $\approx 1300^{\circ} \mathrm{C}$ ) was selected for testing in the EnVitco melter (Andrews, 1993). This study indicated that a glass with a $45 \mathrm{wt} \%$ waste loading (on an oxide basis) could be successfully vitrified into a leach resistant product. Techflo Perlite, a volcanic aluminosilicate powder was used as the glass former additive in these tests. On a dry oxide basis, $55 \mathrm{wt} \%$ Techflo perlite was mixed with $45 \mathrm{wt} \%$ sludge to form the target glass formulation (Table II.7).

\section{II.B.4. Melter Operation}

The EV-16 cold-top melter has two control variables: melter power and feed rate. These two variables were used to maximize the melt rate and throughput. Hot covers for the cold-top melter were used to run the melter in a partial hot-top mode in which unmelted feed covers a portion of the molten glass surface. The slurry feed rate was adjusted so that a steady thickness of batch was on at least a portion of the melt. Melter power was set at $35 \mathrm{~kW}$ per phase and the feed rate was then maximized. To provide additional mixing in the melter, a nitrogen sparge was set up through the back wall electrode directly under the feed inlet. The bubbling helped to break up the feed on top of the melt and mix the glass.

\section{II.B.5. Vitrification Process Challenges}

Vitrification of this waste stream offered several processing challenges. A high temperature glass composition was selected for this vitrification campaign. This composition was anticipated to have a relatively high viscosity at lower temperatures (which would be expected in the drain tube) potentially posing difficulties in discharging the glass from the melter. Additionally, high melt temperatures often enhance corrosion of electrodes or refractories in glass melters.

High calcium contents typically limit waste loading due to the tendency for devitrification through the formation of calcium silicate species. The formation of crystals in the melter can hinder homogenization of the glass and more importantly discharge of glass from the melter.

The presence of organic species can lead to several processing problems. Organic compounds can cause reducing conditions in the glass melt and in the plenum above the melt surface. Since metals in their reduced states tend to be more volatile, an excess of organic compounds could prevent the incorporation of hazardous metals and radionuclides in the glass matrix. If metals are reduced to their elemental state, molten metal may accumulate in the bottom of the melter and eventually short the electrodes. If the melter's 
plenum does not have an excess of oxygen, organic compounds will be pyrolyzed instead of oxidized. This decreases the organic destruction efficiency of the system and result in the production of intermediate organic compounds.

\section{II.B.6. Vitrification Campaign Results}

Nearly three melter volumes of calcium aluminosilicate glass (CAS) were produced in the EnVitco melter during this campaign. The melter was operated for 18 days for about 16 hours per day. Each evening and weekend, the melter was placed on hot hold in which the feed was turned off and the power was decreased. The best estimate as to the temperature of the melt just below the surface was approximately $1400^{\circ} \mathrm{C}$ during normal melting.

The density of the glass produced was $2.63 \mathrm{~g} / \mathrm{cm}^{3}$ and the density of the slurry feed was $1.14 \mathrm{~g} / \mathrm{cm}^{3}$. Considering a loss on ignition of $82 \%$, the volume reduction of the feed was $92 \%$. The decrease in the volume from waste to glass was $82 \%$ based on an oxide waste loading of $41 \%$ by weight.

In general, the analyzed waste glass closely matched the target composition. Although the total iron content in the glass was similar to the target, iron in the form of $\mathrm{Fe}_{2} \mathrm{O}_{3}$ was significantly lower than targeted indicating the reduced nature of the melt. This redox condition does not represent significant problems to corrosion of the molybdenum electrodes in the EnVitco melter. However, the potential for reducing metal species from the melt and potentially shorting the electrodes warrants consideration. The small increase in $\mathrm{Al}_{2} \mathrm{O}_{3}$ content in the analyzed glass likely resulted from corrosion of the flux block refractory during the campaign (see below).

The durability and leach resistance of the glass produced in these tests were excellent. The Product Consistency Test (PCT) results showed that the leaching of $\mathrm{Na}, \mathrm{B}$ and $\mathrm{Si}$ were all almost two orders of magnitude lower in the CAS glass than in the Environmental Assessment (EA) glass. The results from the Toxic Characteristic Leaching Procedure (TCLP) analysis were equally as promising. In this case, leaching results for all hazardous metals was at least an order of magnitude lower than the Land Disposal Regulatory (LDR) limits.

The CAS glass chosen for the EnVitco melter had a high melting point, relatively high viscosity, and had a tendency to devitrify to form a crystalline material. These glass properties led to some operational problems with the melter.

Due to the high viscosity, a continuous output of glass at the same rate as the melter was fed batch materials could not be maintained. Instead, the melter was generally operated with continuous feed and intermittent output as required to control the melt level. 
WSRC-TR-95-0412

Page 17 of 53

September 29, 1995

Table II.7. WETF Glass Compositions Expressed in Mass Percent.

\begin{tabular}{|c|c|c|c|c|c|c|}
\hline \multirow[t]{3}{*}{ Oxide } & \multirow{2}{*}{\multicolumn{2}{|c|}{$\begin{array}{l}\text { EnVitco Test } \\
\text { CAS Glass }\end{array}$}} & \multicolumn{4}{|c|}{ Stir-Melter Test } \\
\hline & & & \multicolumn{2}{|c|}{ BS Glass } & \multicolumn{2}{|c|}{ SLS Glass } \\
\hline & Target & Analysis & Target & Analysis & Target & Analysis \\
\hline $\mathrm{Al}_{2} \mathrm{O}_{3}$ & 13.53 & 15.05 & 7.59 & 7.22 & 4.56 & 4.52 \\
\hline $\mathrm{BaO}$ & 0.07 & 0.06 & 0.05 & 0.05 & 0.03 & 0.03 \\
\hline $\mathrm{B}_{2} \mathrm{O}_{3}$ & 0.00 & 0.08 & 15.67 & 15.5 & 0.00 & 0.00 \\
\hline $\mathrm{CaO}$ & 21.74 & 20.50 & 25.89 & 25.85 & 18.98 & 21.0 \\
\hline $\mathrm{CdO}$ & 0.00 & 0.00 & 0.00 & 0.00 & 0.00 & 0.00 \\
\hline $\mathrm{CeO}_{2}$ & 0.11 & 0.22 & 0.13 & 0.14 & 0.10 & 0.14 \\
\hline $\mathrm{Cl}$ & 0.00 & $\mathrm{ND}^{1}$ & 0.00 & 0.02 & 0.00 & ND \\
\hline $\mathrm{Cr}_{2} \mathrm{O}_{3}$ & 0.04 & 0.04 & 0.05 & 0.12 & 0.03 & 0.07 \\
\hline $\mathrm{CuO}$ & 0.11 & 0.09 & 0.11 & 0.08 & 0.08 & 0.06 \\
\hline $\mathrm{Fe}_{2} \mathrm{O}_{3}{ }^{2}$ & 1.78 & 0.20 & 2.11 & 0.00 & 1.02 & 0.02 \\
\hline $\mathrm{FeO}$ & 0.00 & 1.37 & 0.00 & 1.95 & 0.00 & 0.93 \\
\hline $\mathrm{K}_{2} \mathrm{O}$ & 3.80 & 3.19 & 0.14 & 0.21 & 0.00 & 0.07 \\
\hline $\mathrm{Li}_{2} \mathrm{O}$ & 0.00 & 0.03 & ND & 0.00 & 7.49 & 7.21 \\
\hline $\mathrm{MgO}$ & 0.85 & 1.04 & 1.04 & 1.12 & 0.69 & 0.86 \\
\hline $\mathrm{MoO}_{3}$ & 0.00 & 0.27 & 0.00 & 0.00 & 0.00 & 0.00 \\
\hline $\mathrm{Na}_{2} \mathrm{O}$ & 4.77 & 4.46 & 10.71 & 10.90 & 10.08 & 9.00 \\
\hline $\mathrm{NiO}$ & 0.10 & 0.10 & 0.12 & 0.15 & 0.08 & 0.17 \\
\hline $\mathrm{P}_{2} \mathrm{O}_{5}$ & 0.41 & 0.60 & 0.60 & 0.49 & 0.34 & 0.38 \\
\hline $\mathrm{PbO}$ & 0.02 & 0.08 & 0.03 & 0.09 & 0.02 & 0.08 \\
\hline $\mathrm{SiO}_{2}$ & 52.42 & 51.50 & 35.78 & 35. & 56.51 & 54.50 \\
\hline $\mathrm{SO}_{3}$ & 0.00 & ND & 0.00 & 0.01 & 0.00 & $\mathrm{ND}$ \\
\hline Total & 99.03 & 99.75 & 99.91 & 99.01 & 100.00 & 99.18 \\
\hline
\end{tabular}

${ }^{2}$ In the target composition, all $\mathrm{Fe}$ was assumed to be $\mathrm{Fe}_{2} \mathrm{O}_{3}$. 
In addition, when the melter was put into hot idle conditions overnight and during the weekend, the glass had a tendency to devitrify forming wollastonite $\left(\mathrm{CaSiO}_{3}\right)$, which has a melting point above $1800^{\circ} \mathrm{C}$. When this occurred, the melter was very difficult to drain. This often necessitated cooling the melter, removing the devitrified material, and restarting the melter. Additional flux, such as soda, would probably alleviate this operating problem. However, this would also likely require a reduction of waste loading (calcium content) to maintain adequate glass durability.

During the first part of the actual demonstration, power control and power failure problems impeded the test. Zone 1, the left and right side wall electrodes, was consistently operating at a higher power than zone 2 , the front and back wall electrodes. Zone 2 had the nitrogen sparge through its back wall electrode. It is possible that the resistance between zone 2 electrodes was higher than that of zone 1 due to the nitrogen bubbles. This increased resistance caused an unbalanced load on the transformer and the unit could not be controlled properly. It is possible that if a sparge was set up between the zone 1 electrodes then the load would have been balanced, and no power overload problems would have been experienced.

After the demonstration was complete, the melter was disassembled and inspected for corrosion. Near the refractory, the electrodes were thinner than their original diameter. Since this end of the electrode should not have been in a high current density, high temperature region, this points to a chemical mechanism such as corrosion. Alloying of the molybdenum with another metal such as nickel was possible. When one of the electrodes was broken in removing the glass, it was noted that the grain size of the molybdenum had increased to about $3 \mathrm{~mm}$. The grains in the original molybdenum rods were not noticeable to the eye.

For comparison purposes two different refractories were used. All four refractory walls were cracked in many places due to thermal shock and stress upon thermal cycling. The three walls made of flux block were severely corroded. Next to the electrodes, this refractory was only about $0.5^{\prime \prime}$ thick. The total amount of material lost from these three walls was approximately $20 \mathrm{~kg}$. The high chrome content, sintered refractory used for the fourth wall exhibited excellent corrosion resistance. Only minor pitting was evident.

\section{II.C. Rocky Flats Plant (RFP) Precipitate Sludge}

\section{II.C.1. Test Objectives}

The principal objectives of this melter campaign were to demonstrate the feasibility of vitrifying RFP precipitate sludge in a continuously operated Joule heated melter and to characterize the environmental impact of the vitrification process. The test program was 
aimed at obtaining information relating to: product quality, offgas emissions characterization, material balances, and melter behavior and performance. A summary of the data relating to melter operation from this study is provided below.

II.C.2. Waste Composition

The Rocky Flats Plant precipitate sludge originates from treatment (chemical precipitation) of aqueous waste from $\mathrm{Pu}$ recovery operations, and thus is a transuranic derived (TRU) waste. Four different wastes are generated from this process, but the sludge to be tested can be considered either first or second stage sludge. The first stage of the solidification operation is a chemical precipitation of radioactive elements from the liquid wastes. The chemicals used in the precipitation are ferric sulfate, calcium hydroxide, magnesium sulfate, and coagulants. The resulting sludge is concentrated using a filter press coated with diatomaceous earth filter aid. A thin layer of this filter cake is continuously cut from the drum filter, which produces a wet sludge with a water content of up to $60 \%$, and an effective waste loading of about $40 \%$ dry solids (Cicero, 1994).

Plutonium is the primary radionuclide in the waste stream. The sludge also contains small amounts of chromium, nickel, lead, cadmium, and silver. From a regulatory perspective, this means that it contains solvents or compounds to make it a F001, F002, and F005A Resource Conservation and Recovery Act (RCRA) waste. A surrogate waste formulation was developed and is listed in Table II.8.

\section{II.C.3. Glass Formulation}

A borosilicate glass with mid-range melting temperature of $\approx 1150^{\circ} \mathrm{C}$ was chosen for the glass formulation to be demonstrated in the Envitco EV-16. The feed composition was based on a $50 \mathrm{wt} \%$ waste loading (on a dry oxide basis). Glass forming additives, on a dry oxide basis, consisted of $14 \mathrm{wt}$. \% Borax, $36 \mathrm{wt} \%$ Diatomaceous Earth, and $3 \mathrm{wt} \%$ aluminum oxide. The glass formulation was determined by SRTC and based on a combination of crucible studies and glass formulation models (Cicero, 1994). The aluminum oxide was added to increase the viscosity of the glass to a level suitable for draining from the EV-16. In addition to the glass forming additives, activated carbon at 3 wt $\%$ was chosen as a feed additive to control the formation of sulfate salts. Crucible studies by Cicero and Andrews at SRTC found activated carbon addition at $3 \mathrm{wt} \%$ to be sufficient to eliminate salt formation (Cicero, 1994). 
Table II.8. RFP Precipitate Surrogate Composition

\begin{tabular}{cc}
\hline \hline Oxide & Weight \% (Dry Oxide Basis) \\
\hline $\mathrm{SiO}_{2}$ & 7.326 \\
$\mathrm{Al}_{2} \mathrm{O} 3$ & 0.529 \\
$\mathrm{CaO}$ & 15.068 \\
$\mathrm{Na} 2 \mathrm{O}$ & 7.132 \\
$\mathrm{Fe}_{2} \mathrm{O}_{3}$ & 22.071 \\
$\mathrm{MgO}$ & 8.402 \\
$\mathrm{Cr} 2 \mathrm{O} 3$ & 0.120 \\
$\mathrm{CdO}$ & 0.094 \\
$\mathrm{CeO} 2$ & 0.096 \\
$\mathrm{NiO}$ & 0.104 \\
$\mathrm{PbO}$ & 0.088 \\
$\mathrm{AgO}$ & 0.088 \\
$\mathrm{Total}$ & 61.118 \\
\hline
\end{tabular}

II.C.4. Melter Operation

The EV-16 cold-top melter has two main process control variables: melter power and feed rate. These two variables were used to maximize the melt rate and throughput. Fiberfrax covers for the cold-top melter were used to run the melter in a partial hot-top mode in which unmelted feed covers a portion of the molten glass surface. The slurry feed rate was adjusted to keep a steady thickness of batch on at least half the surface of the melt. Melter power was set at $30 \mathrm{~kW} /$ phase and the feed rate was maximized.

The surrogate slurry fed to the melter had a $55 \mathrm{wt} \%$ solids content and a $45 \mathrm{wt} \%$ water content.

\section{II.C.5. Vitrification Process Challenges}

Three components of the sludge were of an unusual nature and were the focus of potential processing problems. Calcium sulfate, sodium nitrate, and iron oxide constituted $77.5 \mathrm{wt}$ 
$\%$ of the dry sludge and $38.75 \mathrm{wt} \%$ (dry basis) of the waste loading fed to the EV-16. Vitrifying a waste with these components in such abundance had yet to be attempted.

High calcium content typically places limitations on waste load processing due to the tendency for devitrification through the formation of calcium silicate species. The formation of crystals in the melter can hinder homogenization of the glass and, more importantly, discharge from the melter. Also, the presence of calcium sulfate introduces competing processes into the melt. Calcium sulfate is a stable compound that melts at temperatures $>1400^{\circ} \mathrm{C}$ and has a density that is significantly less than typical waste glasses. Calcium sulfate can react with alkalis to produce alkali sulfates. Sulfates have a limited solubility in glass. It is therefore possible that the sulfate salts will melt, float on the molten surface, and hinder incorporation of the calcium into the glass due to the low solubility of a stable sulfate salt.

Sodium nitrate poses process challenges in two areas: offgas and glass processing. Sodium nitrate decomposes at $\approx 600^{\circ} \mathrm{C}$ to sodium oxide and nitrogen oxides (primarily $\mathrm{NO}, \mathrm{NO}_{2}$ ). $\mathrm{NO}_{\mathrm{x}}$ emissions are respiratory irritants and toxic in sufficient quantities and are regualted under the Clean Air Act (CAA). It is therefore necessary to monitor and treat $\mathrm{NO}_{\mathrm{x}}$ emissions as they are evolved. In terms of glass processing, it is possible for the sodium and sulfate within the feed to interact on the melt surface and form sodium sulfate. Sodium sulfate, like calcium sulfate, is a stable salt even at high melter temperatures. Sodium sulfate has many of the same characteristics of calcium sulfate and could hinder incorporation of sodium, a major glass component and fluxing agent, into the glass. The overall impact of sulfate salt formation on the demonstration could be the formation of a glass deficient in calcium and sodium with physical and chemical properties greatly different from the target glass composition.

The potential for sulfate salt processing problems is extremely high. Activated carbon, at a waste loading of $3 \mathrm{wt} \%$ (dry basis), was added to the feed material in an attempt to reduce the sulfate salts to gaseous $\mathrm{SO}_{2}$ which may be treated in the offgas system. However, introduction of a strong reducing agent such as activated carbon could cause excessively reducing conditions in the glass melt. Since metals in their reduced states tend to be more volatile, an excess of activated carbon could prevent the incorporation of hazardous metals and radionuclides into the glass matrix.

\section{II.C.6. Vitrification Campaign Results}

Three melter volumes of borosilicate glass were produced in the EV-16 melter during this campaign. The melter was operated for 19 days: 10 days semi-continuous averaging 10 hours per day and 9 days of continuous 24 hours per day operation. During the 10 days of semi-continuous operation melter parameter studies were conducted to optimize glass melt rate. At the end of these daily studies, the melter was placed on "hot hold" in which 
WSRC-TR-95-0412

Page 22 of 53

September 29, 1995

the feed was turned off and the power was decreased. The best estimate as to the temperature of the melt just below the surface during continuous operation was approximately $1300-1350^{\circ} \mathrm{C}$.

The melter was fed a total of $802.87 \mathrm{~kg}$ of feed (dry basis) at an average feed rate of 0.035 gpm. A total of $641.1 \mathrm{~kg}$ of glass was intermittently drained from the melter over the total duration of the run (19 days). Analyses of the characteristics of the glass produced, specifically Product Consistency Test (PCT) and Toxic Characteristic Leaching Procedure (TCLP) are currently underway.

Several processing problems arose throughout the vitrification demonstration. Of greatest concern was the extremely slow melt rate. The melt rate was sufficiently low that the EV16 drain rate could not match the melt rate. Two basic observations about the formulation directly affected the slow processing rate of the waste: 1) reactive offgassing and foaming, and 2) sulfate salt formation.

The evolution of offgas, primarily in the form of $\mathrm{NO}_{\mathrm{x}}$ from the decomposition of sodium nitrate, was vigorous. This created a boiling melt surface which at times had as much as four inches of foam. The presence of thick foam layers and boiling reduced the effectiveness of operating in a cold top mode and decreased the melt rate. To operate on a continuous feed basis, it was necessary to cover only half of the molten glass surface with unmelted batch. This reduced the boiling intensity by venting generated offgas through the molten glass surface and helped to reduce the thickness of the foam layer.

The intensity of the boiling/offgassing was directly related to the power input:to the melt. As power to the melt was increased, boiling of the melt increased. It was possible to gradually raise the power to the melt without greatly increasing the boiling of the melt surface. This was effective up to a power setting of $30 \mathrm{~kW} / z$ zone. At power levels greater than $30 \mathrm{~kW} / z o n e$, offgassing became too vigorous to operate the melter in a safe manner.

The presence of a foam layer also affected the drain procedure. During feeding it was impossible to accurately determine the true glass level within the melter. In order to avoid draining glass below the level of the electrodes, feeding was stopped ten to fifteen minutes before beginning to drain. This allowed the melt to degas which eliminated the foam layer. A true melt level could then be determined and draining could safely commence. Once the melt level was lowered, glass draining was stopped and feeding began again. The cycle of feed-degas-drain-feed greatly contributed to the overall slow melt rate.

Sulfate salt formation impeded the processing of the RFP sludge by forming a layer of molten salt that floated on the surface of the glass melt. The molten salt layer slowly volatilized or was entrained with particulate matter into the offgas system. On two 
WSRC-TR-95-0412

Page 23 of 53

September 29, 1995

separate occasions, a combination of particulate matter and condensed sulfate salts of calcium and sodium plugged the offgas riser just above the melter plenum. The blockage forced the melter plenum into a positive head pressure situation which allowed $\mathrm{NO}_{\mathrm{x}}$ gases to escape the melter containment. Feeding of the melter was ceased until the blockage was cleared. The water-soluble salts also managed to bypass the offgas system and condense within the blower. In time the salt buildup shutdown the main offgas blower requiring the cessation of any feeding until the blower could be cleaned. This usually required the melter to be on "hot hold" for a day and happened three times during the initial stages of the RFP demonstration. The final result of sulfate salt formation is significant amounts of glass network modifiers, calcium and sodium, were collected in the offgas system and not incorporated into the glass.

Analyses of the glass produced in the RFP demonstration are underway. Visual inspection of the glass during production suggests the waste has similar devitrification tendencies of previous high calcium wastes (Hewlett, 1994). The RFP glass had a tendency to form crystalline cores within the graphite crucible monoliths upon cooling.

After the demonstration was complete, the melter was disassembled and inspected. The electrodes and refractories both exhibited evidence of significant degradation.

Each electrode lost approximately 4 inches of its length during the testing. The electrode surface was noticeably pitted with a brownish film covering most of the exposed end. Elemental examination of the surface film by $x$-ray fluorescence indicated the presence of iron, nickel, copper and arsenic. Metallographic examination of the electrode is currently underway. Initial observations indicate apparent alloying at the tip of the electrode and some evidence of grain boundary attack.

A number of metallic pellets were retrieved from the bottom of the melter following the trial. Preliminary analysis of the pellets indicated the presence of nickel, iron and copper. Also present in the pellets was molybdenum and/or sulfur. Due to the overlap of the dominant energy dispersive spectroscopy (EDS) peaks of Mo and S, it was not initially apparent if either and/or both were present in the pellets. However, due to the noticeable attack of the electrodes, it is likely that molybdenum was present in the pellets.

Based on some preliminary analysis, the following is speculated regarding the degradation of the electrode. Due to the reducing conditions in the melter (exacerbated by the high sulfate concentration), metals present in the feed were reduced (namely $\mathrm{Fe}, \mathrm{Ni}, \mathrm{Cu}$ and As). These metals either elementally or as sulfides attacked the electrode causing extensive degradation. Iron, nickel and copper likely alloyed with the molybdenum, while it is speculated that the arsenic attacked the grain boundaries in the molybdenum. 
WSRC-TR-95-0412

Page 24 of 53

September 29, 1995

The refractories were also examined following the tests. For comparison purposes, four different materials were used for the walls of the melter. The four materials used included: an alumina-zirconia-silicate (AZS) sintered refractory, an AZS fused cast refractory, a high chrome, pressed refractory, and a chromium-aluminum-zirconium-silicate fused cast refractory. The AZS sintered refractory was heavily damaged near the electrode openings losing approximately 2 " of the 3 " thickness in this area. The other 3 refractories performed better than the AZS sintered refractory with the only noticeable damage near the electrode openings. The AZS fused cast refractory lost about $7 / 8^{\prime \prime}$ of its 3 " thickness in this region. Approximately $1 / 2$ " of the high chrome, sintered refractory 3 ". wall thickness was lost near the electrode opening during the trial. The $\mathrm{Cr} / \mathrm{Al} / \mathrm{Zr}$ silicate fused cast refractory exhibited negligible degradation and was not removed from the melter.

\section{II.D. Lessons Learned}

The three vitrification campaigns performed with the EnVitco melter provided a significant amount of melter operation data to the low-level waste vitrification program. Generally, good, homogeneous glass products were produced during these campaigns. The glasses typically had excellent durabilities and leach resistance. Several processing difficulties were noted, however, during the vitrification tests. The major problems were: devitrification of the glass in the melter, corrosion of the electrodes, corrosion and/or erosion of refractories, difficulty in controlling the melt and pour rates and entrainment of fines during dry feeding. A summary of melter operation and performance during the vitrification campaigns is shown in Table II.9.

During the Oak Ridge Reservation WETF and Rocky Flats Precipitate Sludge.campaigns significant devitrification of the glass occurred. This was attributed to the relatively high calcium contents in these glass formulations. As observed, calcium silicate phases readily formed during glass processing. This caused extreme difficulties in discharging glass from the melter. At various times in an attempt to keep a consistent melt pool and facilitate glass pouring, the melter was operated at high temperatures which caused several other problems (see below). Devitrified material clogged the drain tube requiring manual "rodding" of the drain tube to allow glass to drain from the melter. Following testing, devitrified material was typically found in "cooler" areas of the melter (i.e. at the refractory walls, on the floor of the melter, on the drain tube, on the base of the electrodes, etc.). This undoubtedly affected mixing and homogenization of the glass batch during processing.

A number of lessons were learned from the devitrification behavior. There definitely appears to be a limit on the amount of calcium which can be readily incorporated into a waste glass. It appears that the $\mathrm{CaO}$ content should be kept below approximately 
WSRC-TR-95-0412

Page 25 of 53

September 29, 1995

Table II.9. EnVitco Melter Operation Summary

\section{Melter Campaign}

$\begin{array}{llll} & \text { M-Area Sludge } & \text { WETF Sludge } & \begin{array}{l}\text { Rocky Flats } \\ \text { Precipitate sludge }\end{array} \\ \text { Glass Type } & \begin{array}{l}\text { Soda-Lime-Silica, } \\ \text { Borosilicate }\end{array} & \begin{array}{l}\text { Calcium } \\ \text { Aluminosilicate }\end{array} & \text { Borosilicate } \\ \text { Waste Loading } & \begin{array}{l}80 \mathrm{wt} \%, 90 \mathrm{wt} \%, \\ 95 \mathrm{wt} \%\end{array} & 45 \mathrm{wt} \% & 50 \mathrm{wt} \% \\ \text { Feeding } & \text { Dry } & \text { Slurry } & \text { Slurry } \\ \text { Melt Cap } & \text { Cold Top } & \text { Partial Hot Top } & \text { Partial Hot Top } \\ \begin{array}{l}\text { Melter Power } \\ \text { (per phase) }\end{array} & \approx 60 \mathrm{~kW} & 35 \mathrm{~kW} & 30 \mathrm{~kW} \\ \begin{array}{l}\text { Process } \\ \text { Challenges }\end{array} & \begin{array}{l}\text { Dry feeding } \\ \text { Ni incorporation }\end{array} & \begin{array}{l}\text { High temp. glass } \\ \text { High Ca content } \\ \text { Organic species }\end{array} & \begin{array}{l}\text { High Ca content } \\ \text { High sulfate conc. } \\ \text { High nitrate conc. }\end{array} \\ & & \text { Devitrification } & \begin{array}{l}\text { Devitrification } \\ \text { Off-gas pluggage }\end{array} \\ \begin{array}{l}\text { Process } \\ \text { Difficulties }\end{array} & \begin{array}{l}\text { Feed entrainment } \\ \text { Off-gas pluggage }\end{array} & \text { Refractory wear } & \text { Foaming } \\ & \begin{array}{l}\text { Electrode wear } \\ \text { Refractory wear }\end{array} & & \begin{array}{l}\text { Electrode wear } \\ \text { Refractory wear }\end{array}\end{array}$


$18 \mathrm{wt} \%$ for practical processing of these wastes. Secondly, it is obvious that there is a significant jump in scaling from crucible melts to actual melter processing. A greater effort appears necessary for determining applicable glass properties during the crucible tests. Liquidus temperatures, devitrification behavior and glass viscosity over a range of temperatures should be determined before processing in the melters.

Significant corrosion of the molybdenum electrodes was observed following the SRS MArea and Rocky Flats trials. Under extreme conditions of high melt temperatures and reducing conditions, alloying of the electrodes with reduced metal constituents was prevalent. Nickel precipitation and alloying was evident in both melter runs indicating the need to carefully monitor the nickel content in the glass and the redox conditions of the melt. The presence of arsenic (likely as an impurity in the raw materials) must be considered due to the potential for extreme, rapid degradation of the electrodes through grain boundary attack under reducing conditions. This is especially important due to the extreme grain growth observed at the tips of the electrodes.

The flux block refractory was extensively corroded and/or eroded following each run. In the Rocky Flats campaign, an AZS sintered refractory also degraded significantly. The corrosion was likely exacerbated by relatively high temperatures in the melter. The corrosion of the refractories appeared to be non-linear and likely ceased when a critical refractory thickness was reached due to cooling of the melter shell. The other refractories tested (AZS fused cast and high chrome refractories) generally performed very well during the testing with very little corrosion evident. Due to the nature of treating hazardous and radioactive wastes, it is recommended that either AZS fused cast or high chrome refractories be used in actual radioactive melter operation.

Continuous melter operation (i.e. continuous feeding and pouring) is desirable for radioactive waste processing. This was not the typical mode of operation during these tests as more of a batch operation evolved. Generally, the feed was not incorporated into the melt at a fast enough rate to allow for continuous glass tapping. This was likely due in part to the refractoriness and high viscosities of some of the glass formulations and to the relatively small size of this melter. Difficulties in determining melt levels in the melter also necessitated this mode of operation in some cases.

Dry feeding in the M-Area tests caused significant off-gas system pluggage. The relatively fine particle size of glass former components (i.e. perlite and precipitated silica) led to entrainment into the off-gas system. The use of carbonates and hydrates also caused some problems during testing using the "first generation" off-gas system. Dampening the feed or pelletizing may have corrected this problem, since this behavior was not evident during slurry feeding. 
WSRC-TR-95-0412

Page 27 of 53

September 29, 1995

\section{Stir-Melter Test Campaigns}

Stir-Melter WV-0.25: Clemson University's WV-0.25 Stir-Melter is one of three stirred melters in operation. Although it originally was of Inconel'TM 601 construction, it now has an Inconel ${ }^{\mathrm{TM}} 690$ melt chamber with a 6" $\times 6$ " $\times 12$ " high working volume and an Inconel ${ }^{\mathrm{TM}} 690$ stirring electrode. A schematic of the melter is shown in Figure III.1. Maximum processing temperature is limited to $\approx 1070^{\circ} \mathrm{C}$ because of the materials of construction. The melt chamber has an internal "tea pot" spout with an external drain tube, allowing for continuous operation. The melter has separate ports for dry feeding and slurry feeding of the batch and other additives.

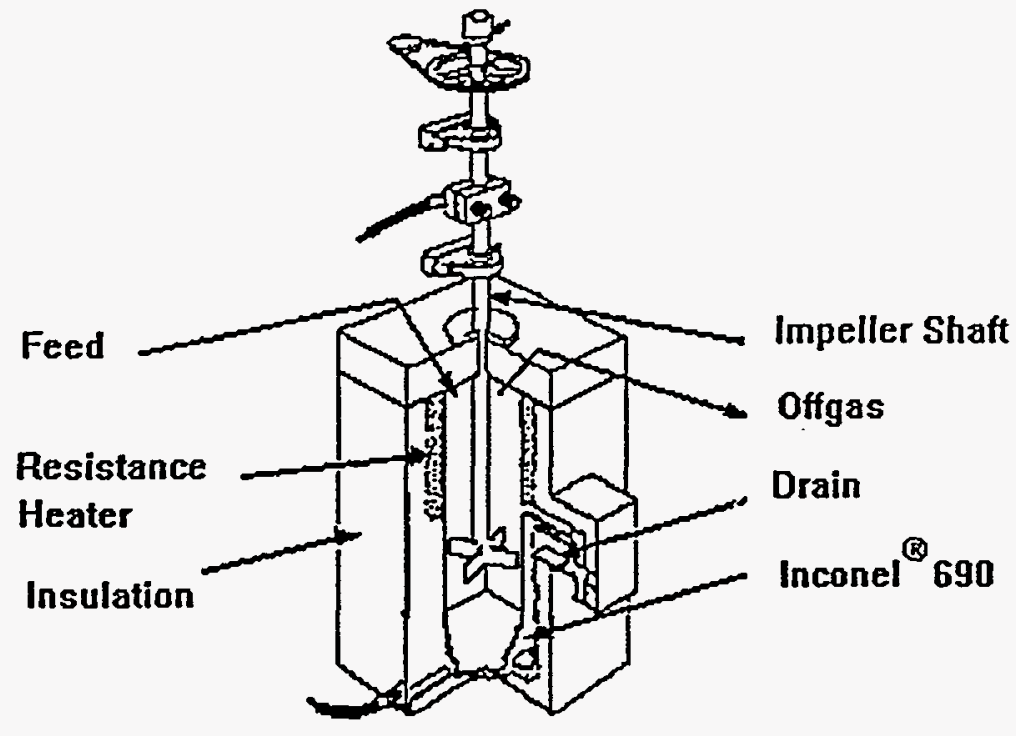

Figure III.1. Schematic of the WV-0.25 Stir-Melter with the Inconel ${ }^{\mathrm{TM}}$ Vessel

The stirrer is driven by a $1 / 2 \mathrm{hp} \mathrm{(325} \mathrm{W)} \mathrm{variable} \mathrm{speed} \mathrm{motor} \mathrm{at} \mathrm{speeds} \mathrm{up} \mathrm{to} 1000 \mathrm{rpm}$. The impeller can be raised or lowered to optimize mixing and melting rates. Current is transferred to the impeller shaft through a spring-loaded pair of graphite brushes. Temperature measurements are made with thermocouples mounted in fixed positions on the outside of the melter vessel and the drain. Several of these thermocouples are used for the power control system.

There is a port for either a video camera or direct viewing. An air-cooled video camera has been used to observe the melter. There is an additional port for the insertion of a thermocouple or other probe into the melt.

Power supply: Ten kVA power is available for Joule heating through the stirrer/chamber circuit. In addition, there are external resistance heaters with a $7 \mathrm{kVA}$ power supply for startup and to maintain temperatures during tests. These auxiliary heaters are mounted 
WSRC-TR-95-0412

Page 28 of 53

September 29, 1995

along the length of the vessel and are operated by a single power supply and controller. There is a separate bar heater for the melter drain. Each power supply is controlled with a Watlow power controller.

Offgas Sampling: The offgases flow into a sampling and treatment system. Sampling is done downstream of the melter exit at the center of a.2" Schedule 40 pipe. The system has a spray quench/ejector venturi and offgas flows through a jet sparging system. The gases next flow into a 6" (152 mm) diameter Pyrex packed column. Initially this column was packed with about $54^{\prime \prime}(1.37 \mathrm{~m})$ of $1 / 2$ " $(12.7 \mathrm{~mm})$ glass Raschig rings and plastic mesh demister. Currently, it is packed with 1 "Norpac packing. This scrubbing system can be used for neutralization of acid gases released from the melter by the addition of a $\mathrm{pH}$ controller and caustic feed system. The gases are pulled through a positivedisplacement, rotary blower and are exhausted to the atmosphere.

\section{III.A. Savannah River Site (SRS) M-Area Sludge}

\section{III.A.1. Test Objectives}

The objective of this test program was to demonstrate vitrification of surrogate M-Area sludge glass formulations in the stirred melter (Bennert, 1995). The conditions were varied by using various levels of added flux (sodium and boron as borax) to show the effects of changing waste loadings, melting temperatures, and glass characteristics. The process was evaluated based on general melter performance, processing rates, offgas characterization by EPA Method 5, glass leachability according to the Environmental Protection Agency (EPA) Toxicity Characteristic Leaching Procedure (TCLP) and the Product Consistency Test (PCT). The results from the testing pertaining to melter operation is summarized in this section.

\section{III.A.2. Waste Composition}

The waste composition is described in section II.A.2. of this report.

\section{III.A.3. Glass Composition}

Glass formulations were developed by SRTC (Jantzen, 1993). Tailoring the formulations to the waste and the melters required consideration for the melting point, viscosity, leach resistance, and waste loading. Particular attention was necessary when developing a formulation for the Stir-Melter, due to the sensitivity of the melter to the glass melting point and the viscosity. The Inconel TM 690 has a melting point of about $1350^{\circ} \mathrm{C}$, but the creep rate increases with a decline in the elastic modulus above $1100^{\circ} \mathrm{C}$. Since both the impeller and the vessel walls experience stress from the mixing action, the operating temperatures were limited to reduce the potential for excessive creep of the two components. In an effort to minimize the potential for damage to the impeller or vessel, 
the Inconel TM 690 components were limited to operating temperatures of $1050^{\circ} \mathrm{C}$. As more application information is generated, it may be determined that the melter is capable of operating at higher temperatures.

The Stir-Melter constraints made it necessary to develop glasses that have low melting temperatures and low viscosities and can be easily processed below $1050^{\circ} \mathrm{C}$. These limits are not applicable to the EnVitco due to the higher temperature capabilities of the molybdenum and refractory construction materials. Initially glass compositions similar to the EnVitco test campaigns were planned for the stirred melter runs. However, it was concluded that $10 \%$ flux and $5 \%$ flux glasses could not be processed through the stirred melter due to the temperature/viscosity constraint. Therefore, formulations consisting of 20\% (Test M2-1) and 15\% (Test M2-2) flux additions were tested in this unit (Table III.1.).

\section{III.A.4. Melter Operation}

The melter was started from empty, and fed the dry M2-1 20\% flux feed through a 1" feed tube with a 0.75 " auger. The melter was operated for approximately two volumes to reach steady state. Because there was no glass in the melter at the time of startup, it was not necessary to process three volumes of glass to flush out the previous composition. The operating parameters for both demonstrations are presented in Table III.2. The melter was operated with the combined input of Joule heating and resistance heating from the secondary heating panels surrounding the vessel, with a setpoint of $1050^{\circ} \mathrm{C}$ at $70 \%$ power $(7 \mathrm{~kW})$. The resistance heaters operated sporadically, cycling on and off between 0 and $70 \%$ capacity $(0-5 \mathrm{~kW})$ as necessary.

III.B.5. Vitrification Process Challenges

Relatively high waste loadings were selected for this campaign ( $80 \%$ and $85 \%$ for Tests M2-1 and M2-2, respectively). Since the stirred melter is limited to process temperatures of $1050^{\circ} \mathrm{C}$, processing of high waste loading formulations was expected to be challenging. Additional processing inherent to this waste stream challenges are discussed in section II.A.5. of this report. 
WSRC-TR-95-0412

September 29, 1995

Table III.1. M-Area Batch Formulations

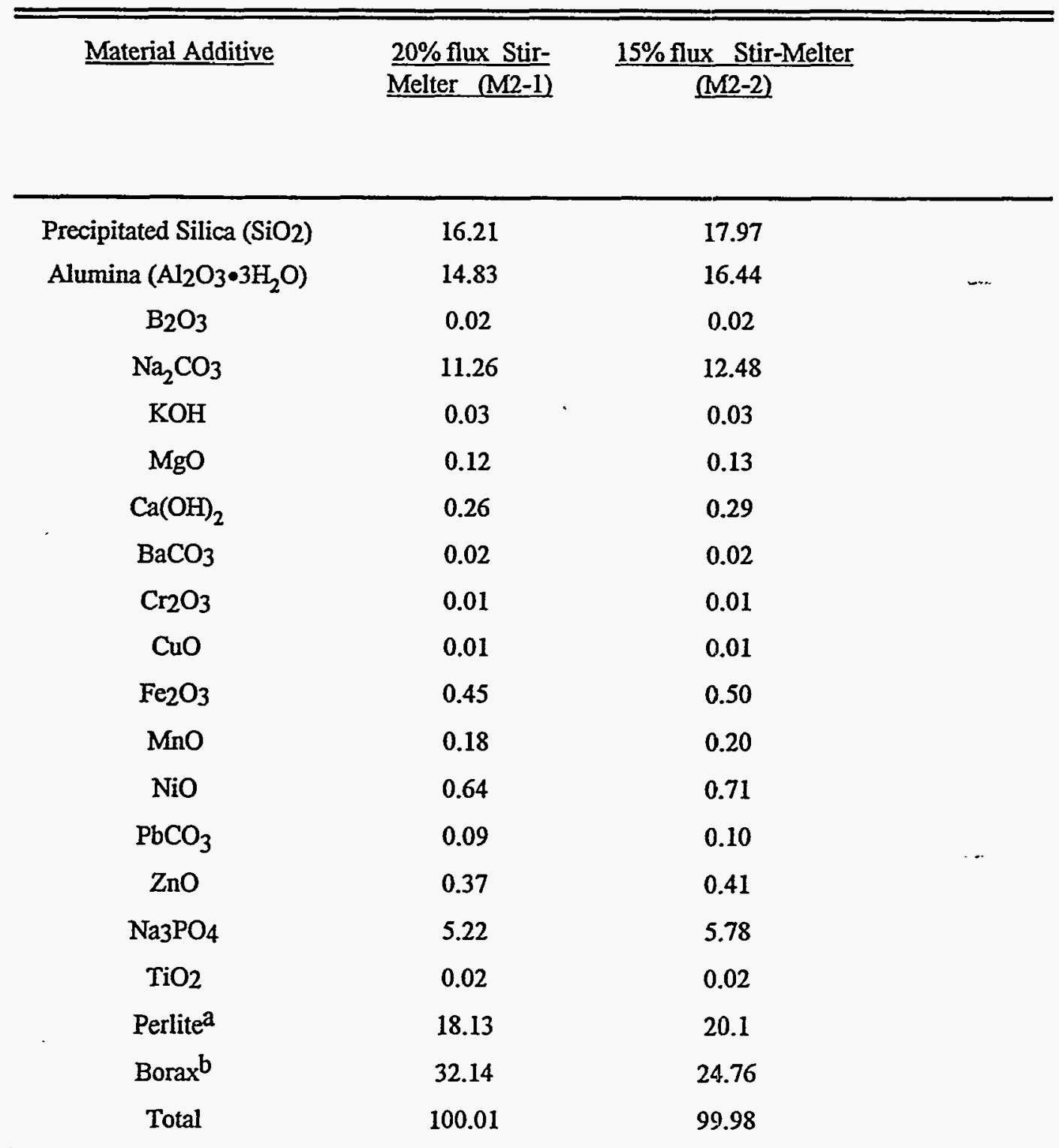

(a) Composition of Perlite as used: $77.40 \% \mathrm{SiO}_{2}, 12.79 \% \mathrm{Al}_{2} \mathrm{O}_{3}, 5.14 \% \mathrm{~K}_{2} \mathrm{O}, 3.12 \% \mathrm{Na} 2 \mathrm{O}, 0.56 \%$ $\mathrm{CaO}, 0.45 \% \mathrm{Fe}_{2} \mathrm{O}_{3}, 0.17 \% \mathrm{MgO}$. Other constituents less than $0.01 \%$.

(b) Borax chemical formula $\left(\mathrm{Na}_{2} \mathrm{~B}_{4} \mathrm{O}_{7} \cdot 10 \mathrm{H}_{2} \mathrm{O}\right)$ 
WSRC-TR-95-0412

Page 31 of 53

September 29, 1995

Table III.2.

Test Matrix and Operating Conditions - Stir-Melter Test Series

\begin{tabular}{cccccccc}
\hline \hline Test & Melter & $\frac{\text { Flux }}{(\%)}$ & $\frac{\text { Power }}{(\mathrm{kW})}$ & $\frac{\text { Voltage }}{(\mathrm{V})}$ & $\frac{\text { Pull Rate }}{(\mathrm{kg} / \mathrm{hr})}$ & $\frac{\text { Feed Rate }}{(\mathrm{kg} / \mathrm{hr})}$ & $\frac{\text { Glass Production }}{(\mathrm{kg})}$ \\
\hline M2-1 & Stir-Melter & 20 & $\sim 7$ & -45 & $\sim 1.5$ & $\sim 2.2$ & $\sim 20$ \\
M2-2 & Stir-Melter & 15 & $\sim 7$ & -45 & $\sim 1.5$ & $\sim 1.9$ & $\sim 20$ \\
\hline
\end{tabular}

III.B.6. Vitrification Campaign Results

Power usage for the Stir-Melter was about $4 \mathrm{kWh} / \mathrm{kg}$ of glass produced, based on $6 \mathrm{~kW}$ average power input. The power requirement would be lower if the melter had been run at capacity, utilizing the full melting potential. The feed rate to the melter was reduced when blockage in the baffles occurred, and emphasis was placed on stable operation at the cost of productivity. No effort was made to optimize throughput, though it is conceivable that power utilization levels of $1-2 \mathrm{kWh} / \mathrm{kg}$ of glass produced could be achieved based on testing conducted by Richards and Jain (Richards, 1993). Additional processing data is listed in Table III.2.

The final glass compositions were generally in good agreement with target compositions (Table III.3.). Minor discrepancies due to analytical error in analyses and difficulty in completely dissolving the batch (e.g. $\mathrm{SiO}_{2}$ ) may account for the differences.

The durability and leach resistance of the tested glasses were very good. The Product Consistency Test (PCT) results showed that the leaching of Na, B, and $\mathrm{Si}$ were all lower in the two glasses tested than in the Environmental Assessment (EA) glass. A significant difference was observed between glasses produced with $15 \%$ flux vs. $20 \%$ flux, however. A 2-3 fold decrease in elemental release was observed in the $15 \%$ flux glasses when compared to the $20 \%$ flux glasses. The Toxic Characteristic Leaching Procedure (TCLP) results were also promising. All elements except $\mathrm{Ni}$ were at or below the detection limit for the analytical system utilized. The Ni concentration in the leachate was below the LDR standards by approximately $8 \%$ in the glasses.

Testing in the Stir-Melter was impaired by problems associated with venting of the melter vessel. As indicated in the earlier EnVitco tests, the dry feed manufactured for the test was very finely divided, and was easily entrained in the exiting gases. The exhaust port exiting the melter plenum was covered by a baffle system that was intended to reduce 
WSRC-TR-95-0412

Page 32 of 53

September 29, 1995

Table III.3.

Analyzed Batch Compositions vs. Final Glass Composition

\begin{tabular}{|c|c|c|c|c|}
\hline \multirow[b]{2}{*}{$\underline{\text { Oxide }}$} & \multicolumn{2}{|c|}{ Stir-Melter M2-1, 20\% Flux } & \multicolumn{2}{|c|}{$\underline{\text { Stir-Melter M2-2, 15\% Flux }}$} \\
\hline & Anal. batch wt \% & Anal. glass wt \% & Anal. wt \% & Anal. glass wt \% \\
\hline $\mathrm{Al}_{2} \mathrm{O}_{3}$ & 16.165 & 15.8 & 19.00 & 19.0 \\
\hline $\mathrm{B}_{2} \mathrm{O}_{3}$ & 16.445 & 16.4 & 12.331 & $\quad 8.5$ \\
\hline $\mathrm{BaO}$ & 0.023 & 0.03 & 0.029 & 0.03 \\
\hline $\mathrm{CaO}$ & 1.026 & 0.87 & 0.544 & 0.59 \\
\hline $\mathrm{Cr}_{2} \mathrm{O}_{3}$ & 0.039 & 0.04 & 0.331 & 0.01 \\
\hline $\mathrm{CuO}$ & 0.009 & 0.02 & 0.022 & 0.02 \\
\hline $\mathrm{Fe}$ (total) & 0.922 & 0.80 & 3.711 & 0.92 \\
\hline $\mathrm{K}_{2} \mathrm{O}$ & 1.083 & 1.16 & 1.141 & 1.37 \\
\hline $\mathrm{MgO}$ & 0.423 & 0.37 & 0.218 & 0.24 \\
\hline $\mathrm{MnO}_{2}$ & 0.305 & 0.31 & 0.492 & 0.32 \\
\hline $\mathrm{Na}_{2} \mathrm{O}$ & 21.48 & 21.2 & 21.731 & 19.1 \\
\hline $\mathrm{NiO}$ & 0.719 & 0.77 & 1.041 & 0.81 \\
\hline $\mathrm{P}_{2} \mathrm{O}_{5}$ & 3.192 & 2.26 & 3.789 & 3.20 \\
\hline $\mathrm{PbO}$ & 0.097 & 0.14 & 0.082 & 0.12 \\
\hline $\mathrm{SiO}_{2}$ & 37.544 & 38.8 & 34.966 & 45.1 \\
\hline $\mathrm{TiO}_{2}$ & 0.041 & 0.04 & 0.044 & 0.08 \\
\hline $\mathrm{ZnO}$ & 0.507 & 0.48 & 0.526 & 0.55 \\
\hline Total & 100.02 & 99.49 & 99.998 & 99.96 \\
\hline
\end{tabular}

entrainment by knocking down any splash or particulate material that reached the plenum exit. The amount of entrainment was excessive, and the buildup of feed material adhering to the baffles completely blocked the exhaust port, causing the vessel to operate at or above ambient pressure. The problem was compounded by the amount of gas generated by carbonate decomposition and release of waters of hydration from the batch additives. All of this resulted in a significant fraction of the feed being forced out of any unsealed areas of the melt chamber. The problem was especially bad with the M2-1, 20\% flux feed, which initially caused the blocked baffles. In order to continue the test, a modification was made to the offgas system to allow the vessel to vent through the camera port. A connection was made to the offgas system downstream of the baffle blockage, and a 
suction line routed back to the camera port. Emissions from the port were then drawn into the suction line and back into the offgas treatment system. This made it possible to operate the melter, but prevented any offgas sampling.

One observation made during this period of the test was the difference in the offgas entrainment between M2-1 and M2-2 compositions. Though no formal sampling was conducted, it was visibly apparent that the emissions from the M2-2 test were only a fraction of those generated in the M2-1 test. The $20 \%$ borax addition may have caused a molten borax layer on the melt surface which influenced this behavior. The difference in gas evolution was insignificant in comparison to the reduction in carryover of feed materials to the offgas. It is feasible that the difference in borax addition and its reactivity in the plenum may have some impact on the entrainment, though this is speculation based on observation.

\section{III.B. Oak Ridge Reservation Y-12 West End Treatment Facility (WETF) Sludge}

\section{III.B.2. Test Objectives}

The principal objectives of this melter campaign were to demonstrate feasibility of vitrifying WETF waste sludge in a continuously operating stirred melter (Hewlett, 1994). The test program was aimed at obtaining information relating to: product quality, off-gas emissions characterization, material balances, and melter behavior and performance. A summary of the data relating to melter operation from this study is provided below.

III.B.2. Waste Composition

The WETF waste composition is discussed in section II.B.2. of this report.

\section{III.B.3. Glass Formulation}

Due to the temperature limits of the stirred melter, two relatively low temperature glass formulations were tested in this effort. The first was a borosilicate (BS) composition with a waste loading of $45 \%$ (Table II.7.). The glass additives to achieve the desired glass were borax and diatomaceous earth in approximately a 1:1 ratio. The second formulation was a low-temperature alkali-lime-silica (ALS) glass with a $35.3 \%$ waste loading (Table II.7.). The glass additives necessary to achieve this composition were: Hubersil 162 - 65 wt $\%$, lithium carbonate - $20 \mathrm{wt} \%$ and sodium carbonate - $15 \mathrm{wt} \%$.

\section{III.B.4. Melter Operation}

Parameters such as melter temperature can dictate the melting rate as well as influence the amount of foaming in the melter. The impeller rotational speed and height can control the rate feed is incorporated into the molten glass. As part of this effort, a parametric study was performed before the demonstration runs in attempt to optimize these processing variables. 
In the parametric study, nine combinations of settings were chosen from previous experience with the melter system. These trials lasted an average of 15 minutes. Each trial was observed and rated using three categories: foam height, glass exit flow, and accumulation on the melt surface. Trials that did not achieve proper conditions were not continued for more than 10 minutes. Trials that resulted in stable operation lasted approximately 25 minutes.

Foam Height: Foaming in glass melts is generally caused by the release of gases including water vapor. Additional foam can be created if the vortex in the melter is so strong that air is pulled into the melt. A stable foam layer may not be desirable because it acts as a heat transfer barrier between the melt pool and the incoming feed. This would lower the melt rate and decrease throughput. Under ordinary operating conditions, feed and glass foam at the surface are constantly pulled into the vortex, but the foamy glass still acts as a heat transfer barrier until the feed is totally incorporated into the dense glass below the surface. For these demonstrations, foaming was attributed to the water vapor released when the slurry was pulled below the surface of the melt. During most of the parameter trials, foaming was minimal. Under conditions such as a high feed rate, fast impeller speed, and maximum impeller height, foaming was extreme. The extreme foaming was probably caused by the vortex action pulling air directly into the melt.

Glass Exit Flow: The drain in the WV-0.25 melter is designed to flow when the melt level has a hydrostatic head of $15.2 \mathrm{~cm}$. A glowbar heater, mounted parallel to the drain, supplied heat to keep the glass molten. In addition, a propane burner was used directly under the drain tip to keep glass flowing. Despite these efforts, devitrification of the glass occurred at low flows in these tests. The crystalline material formed in the outlet had a high melting temperatures. The output of the melter was only a steady drip in the parameter trials.

Accumulation of Feed on the Melt Surface: Preventing a cold cap was the chosen operating mode. During the trials for both glass compositions, operation with the high feed rate always formed a cold cap. The medium feed rates were the maximum feed rates that did not form a cold cap.

The parameter runs resulting in a steady operation were trials 3 and 9 for the borosilicate and trial 5 , with a reduced feed rate, for the soda-lime-silica test. The final settings selected for the demonstrations based on the nine trials are listed in Table III.4. A slurry solids loading of $39 \%$ was targeted for the borosilicate trial while a solids loading of $33 \%$ was specified for the alkali-lime-silica run. 
WSRC-TR-95-0412

Page 35 of 53

September 29, 1995

Table III.4.

Operating Parameters For WV-0.25.

\begin{tabular}{lcc}
\hline \multicolumn{1}{c}{ Parameter } & BS & SLS \\
\hline Temperature, ${ }^{\circ} \mathrm{C}$ & 1050 & 1070 \\
Feed Rate, $\mathrm{mL} / \mathrm{min}$ & 68 & 75 \\
Impeller Height, inch & 3.75 & 3.5 \\
Impeller Speed, rpm & 248 & 330 \\
\hline
\end{tabular}

III.B.5. Vitrification Process Challenges

The vitrification challenges for this waste stream are detailed in section II.B.5. of this report.

\section{III.B.6. Vitrification Campaign Results}

III.B.6.a. Borosilicate Glass Run

The WV-0.25 melter was operated continuously for 33 hours. Fifty-nine kilograms of glass were produced including $9 \mathrm{~kg}$ of glass left in the melter at the end of the test. This corresponds to 5.6 melter volumes of glass. During the demonstration, glass and offgas samples were taken.

There is generally good agreement between the target and actual glass compositions (Table II.7). All iron in the glass, however, was in the reduced oxide form, FeO. This indicates that extreme reducing conditions were present in the melter during the run. The reducing conditions resulted from the presence of yeast and dodecane (added to simulate biomass) in the surrogate. These conditions resulted in the formation of a few metal pellets found in the bottom of the vessel (see below).

The durability and leach resistance of the glass produced in these tests were very good. The Product Consistency Test (PCT) results showed that the leaching of $\mathrm{Na}, \mathrm{B}$ and $\mathrm{Si}$ were better than $25 \mathrm{x}$ lower in these glasses than in the Environmental Assessment (EA) glass. The results from the Toxic Characteristic Leaching Procedure (TCLP) analysis were also acceptable. Leaching results for most hazardous metals were well below the Land Disposal Regulatory (LDR) limits. Leaching of nickel was close to the allowable LDR limit (approximately $5 \%$ lower than the limit). Relatively high leaching of 
nickel may be a result of two factors. With reducing conditions in the melter, nickel metal instead of nickel oxide may have been formed in the melter (see below). Pure metals will form a separate phase and are more likely to be leached. The second factor is the potential formation of nickel sulfide. Under reducing conditions in which the $\mathrm{Fe}^{+2}$ to $\mathrm{Fe}^{\text {total }}$ ratio is greater than 0.25 , it is possible that $\mathrm{Ni}_{3} \mathrm{~S}_{2}$ will form (Bickford, 1991). Since sulfur was detected in the metal pellets after the demonstration, it is highly likely that $\mathrm{Ni}_{3} \mathrm{~S}_{2}$ formed. Due to phase separation, the nickel sulfide can leach at the lower $\mathrm{pH}$ conditions of the TCLP test.

The density of the glass was $2.70 \mathrm{~g} / \mathrm{cm}^{3}$ and the density of the slurry feed was $1.30 \mathrm{~g} / \mathrm{cm}^{3}$. Considering a loss on ignition of $70 \%$ by weight, the decrease in volume from feed to glass was $86 \%$. The decrease in the actual waste volume was lower due to the addition of glass forming compounds to the sludge. The decrease in waste volume from wet wastewater sludge to glass, was $80 \%$ based on a waste loading of $37 \%$ by weight on an oxide basis.

A few short interruptions occurred during the demonstration due to the offgas exit port clogging and due to a worn mixing blade in the feed drum. During the approach to steady state, the offgas exit port in the melter clogged causing a positive gauge pressure in the plenum due to the continual release of water vapor and carbon dioxide. The feed system was shut off for approximately one hour while the clog was manually removed.

The slurry in the feed drum had a density of $1.3 \mathrm{~g} / \mathrm{cm}^{3}$ and a solids content of $39 \%$ by weight. Due to the high solids content and abrasiveness of the diatomaceous earth, the impeller blades failed. The blades were replaced resulting in 45 minutes in which the melter was not fed.

Another problem encountered while operating the melter was the clogging of the drain tube. As the glass traveled down the drain tube, it often devitrified. This crystalline material slowed the glass further and frequently clogged the drain completely. The drain was cleaned with a metal rod.

After 45 hours of operation in the glass bath, the melter impeller showed no signs of significant wear. Some surface pitting and some corrosion were noticeable. The melt vessel had a small hole near the glass exit tube before start-up, but it did not show signs of significant deterioration. After the demonstration was completed, a few small metal pellets were retrieved from the bottom of the melter. The pellets undoubtedly formed as a result of the reducing conditions in the melt. The metal pellets were analyzed by scanning electron microscopy coupled with energy dispersive spectroscopy and were found to contain primarily $\mathrm{Ni}, \mathrm{Cu}, \mathrm{Si}, \mathrm{S}$, and traces of $\mathrm{Cr}, \mathrm{Mg}, \mathrm{Al}$, and $\mathrm{Fe}$. The pellets appeared to be metallic sulfides. 
WSRC-TR-95-0412

Page 37 of 53

September 29, 1995

III.B.6.b. Alkali-Lime-Silica Glass Run

The slurry used for the demonstration was a pseudoplastic gel with a density of $1.2 \mathrm{~g} / \mathrm{cm}^{3}$ and a solids loading of $33 \%$ by weight. Under shear conditions, the gel became very fluid and easily pumpable. Without shear, the gel structure set up and no settling occurred. The $\mathrm{Li}^{+1}$ and the $\mathrm{Na}^{+1}$ ions from the soluble carbonates attract free water in the batch (Funk and Dinger, 1994). With much of the free water bound to ions, the suspension is an inorganic gel structure that is rheologically shear-thinning or pseudoplastic.

The WV- 0.25 melter was run continuously for 38 hours. A total of $57.6 \mathrm{~kg}$ or 5.3 melter volumes was produced including $9 \mathrm{~kg}$ left in the melter at the end of the demonstration. While the melter was processing the third and fourth volumes, samples of the glass were taken to conduct durability tests and compute material balances. Offgas samples were taken from the start of the fourth volume until all the samples were collected. There was only one short interruption in the test due to the feed line clogging. After 24 hours of operation, the feed was stopped for approximately 45 minutes while the feed system was cleaned.

There was again generally good agreement between the target and actual glass compositions (Table II.7). Almost all of the iron in the glass, however, was in the reduced oxide form, $\mathrm{FeO}$. This indicates that extreme reducing conditions were again present in the melter during the run. The reducing conditions resulted from the presence of yeast (added to simulate biomass) and dodecane (added to simulate oil and grease) in the surrogate. These conditions likely contributed to the some of the damage observed in the impeller and melt vessel (see below).

The glass product resulting from this run again exhibited good durability and leach resistance. Product Consistency Test (PCT) results showed that elemental releases for $\mathrm{Na}$ and $\mathrm{Si}$ were at least an order of magnitude lower than the EA glass. The samples passed the land disposal regulation for F006 waste. Relatively high nickel leaching was again observed similar to the borosilicate glass. It may indicate that either nickel metal or nickel sulfide may have formed due the reducing conditions in the glass.

The density of the glass produced was $2.59 \mathrm{~g} / \mathrm{cm}^{3}$ and the density of the slurry feed was $1.22 \mathrm{~g} / \mathrm{cm}^{3}$. Considering a $77 \%$ by weight loss on ignition, the volume reduction of the feed was $89 \%$. The waste volume reduction was $75 \%$ based on an oxide waste loading of $30 \%$ by weight.

The offgas exit port did not clog in this test as it did in the borosilicate demonstration. The gel structure of the alkali-lime-silica slurry may have prevented boiling on top of the glass melt as vigorously as that with the borosilicate slurry. 
WSRC-TR-95-0412

Page 38 of 53

September 29, 1995

Devitrification, encountered with the borosilicate glass, also occurred during the alkalilime-silica demonstration. The drain tube was constantly monitored and periodically cleaned out with a rod. The propane torch was also necessary to keep the glass flowing from the drain tube.

After 38 hours in the alkali-lime-silica glass demonstration, the impeller was severely damaged. The bottom ring of the impeller was missing and severe corrosion of the blades was evident. Large drops of metal were found in the bottom of the melter. A similar failure was observed in previous trials with the stirred melter (Jenkins, 1993). The examination following the 1993 failure indicated that localized extreme temperatures in the impeller caused melting and subsequent rapid degradation. The high temperatures were attributed to excessive localized power dissipation in the electrode. The extreme reducing conditions associated with the WETF campaigns may also have contributed to some degradation in the impeller. The Inconel ${ }^{\mathrm{TM}}$ melt vessel also showed signs of failure. Glass leaked from the melt vessel onto the refractory lining. A hole repaired from previous work may have reopened during the test.

\section{III.C. Ion Exchange Resins}

\section{III.C.1. Test Objectives}

The goal of this effort was to provide a basis for determining the feasibility of vitrifying a cesium-contaminated ion exchange resin in a Joule heated stirred melter (Sargent, 1994). Crucible studies were performed to examine the effects that the presence of organic compounds in a glass melt have on redox ratio, cesium retention and glass formation. Acceptable operating ranges were also determined for the stirred melter through a parametric study.

\section{III.C.2. Waste Composition}

A cation exchange resin was developed at SRS with a Cs capacity four times greater than the best commercial resin (Bibler, 1990). The use of this resin could greatly enhance current efforts to separate and decontaminate high level radioactive wastes at SRS. Moreover, the use of similar ion-exchange resins in commercial nuclear reactors is prevalent and currently there is no definitive treatment technology to stabilize these resin wastes. The resin used in this testing is prepared by condensing the potassium salt of resorcinol with formaldehyde in an aqueous solution. This results in a gel which is dried at approximately $100^{\circ} \mathrm{C}$. The material can be prepared in three separate forms distinguished by the exchangeable cation. Initially, the resin is present in the potassium form. The hydrogen form is prepared by washing the resin present in the potassium form in a dilute solution of nitric acid. A combination potassium/sodium form is prepared by rinsing the potassium resin with $2 \mathrm{M} \mathrm{NaOH}$ solution. For testing in the melter, an ion exchange form 
loaded with non-radioactive cesium was supplied by SRS. The mass ratio of cesium in the loaded form of resin was 0.16 grams of cesium per gram of clean dry resin. It was approximately $38.4 \%$ solids with no free standing water in the container. This resin was also used in crucible testing.

\section{III.C.3. Glass Formulation}

A crucible test program was performed to examine effects of carbonaceous species on glass formation, reducing potential and cesium retention. The basis for the design of the Phase I crucible test matrix was to vary the type of organic material and also to test what effects the addition of water and a sealed environment had on the resulting glass product. Seven combinations of these test conditions were explored. The basic matrix showing the different combinations is shown in Table III.5. Within each combination, the amount of the respective reducing agent was varied. It was not felt that the addition of water would have an effect on an open crucible so that combination was not pursued.

Table III.5.

Basic Matrix for Crucible Study Experiments

\begin{tabular}{ccccc}
\hline \hline Set & Reducing Agent & Reducing Agent $(\mathrm{g})$ & Water & Type of Environment \\
\hline A & Carbon & $0.125,0.25,0.29,0.34,0.375$ & No & Sealed \\
B & Carbon & $0.125,0.25,0.375$ & Yes & Sealed \\
C & Resin & $0.25,0.50,0.75$ & No & Sealed \\
D & Resin & $0.25,0.39,0.50,0.75,0.81$ & Yes & Sealed \\
E & Carbon & $0.125,0.25,0.375$ & No & Unsealed \\
F & Resin & $0.25,0.50,0.75$ & No & Unsealed \\
G & None & None & No & Sealed \\
\hline
\end{tabular}

The following conclusions were made following the crucible studies:

1. The reducing effectiveness of the organic resin used in this research is approximately four times less than elemental carbon on a mass basis.

2. During the crucible study, the average cesium retention for those glass samples which had resin as a reducing agent was 88.6 percent with a standard deviation of 6.6 percent. The average cesium retention for those glass samples which had elemental carbon as a reducing agent and cesium added as cesium carbonate was 66.8 percent with a standard deviation of 4.9 percent.

3. There was no apparent correlation between the final redox state of a glass and the cesium retention based on the crucible study data. 
4. Based on the limited amount of data, the addition of water seemed to result in a more reduced final glass sample.

From this effort, a maximum loading of the resin was determined to be 0.049 grams resin per gram of glass. A combination of high level waste surrogate slurry and ion exchange resin was chosen as the batch materials for the vitrification campaign. The slurry was approximately 35 to 40 weight percent solids. It was made of three components. The first component was a surrogate metal oxide sludge similar to what would be found at the bottom of the waste tanks at SRS. The second component was frit 202, which is a borosilicate glass frit designed by SRS for the vitrification of HLW. The third component, which was present in a minor concentration, was simulated precipitate hydrolysis aqueous (PHA) material. The PHA would likely not be present in the slurry if ion exchange material was used in the separation process. However, the relatively minor concentration of this component was not thought to significantly effect the results of this study. The ion exchange resin was discussed in detail in section III.C.2.

\section{III.C.4. Melter Operation}

A 16 trial parametric study was used to optimize conditions for the vitrification campaign. Melter temperature, impeller speed and height and slurry feed rate were observed to be very important operational parameters. The final melter parameters selected based on the parametric study is shown in Table III.6.

Table III.6.

Stir-Melter Final Operating Conditions

\begin{tabular}{cc}
\hline Parameter & Value \\
\hline Melter Temperature & 1070 degrees Celsius \\
Slumy Feed Rate & $50 \mathrm{~mL}$ min \\
Impeller Height & 4 inches \\
Impeller Speed & $405 \mathrm{rpm}$ \\
Auxiliary Temperature & 1055 degrees Celsius \\
Air Sparger Flowrate & $>800 \mathrm{~mL} / \mathrm{min}$ @ STP \\
\hline
\end{tabular}

III.C.5. Vitrification Process Challenges

The presence of carbonaceous species in a glass melt can cause several processing problems. One potential problem is the formation of soot and tar. Both of these can 
WSRC-TR-95-0412

Page 41 of 53

September 29, 1995

cause plugging in off-gas system equipment. More importantly, these carbon deposits can cause sulfidization or carburization of melter equipment. Depending on the type of redox environment, alloys can be attacked moderately or severely. Inconel ${ }^{\mathrm{TM}} 690$ placed in a reducing environment showed "catastrophic" sulfidization (Bickford, 1986).

Redox control of the glass melt is an important process operation. It is done by balancing the amount of reducing agents and oxidizing agents in the feed and plenum. For a complex feed which includes organic compounds, the redox state of the waste glass is found by balancing the reducing potential of feed organic compounds and the oxidizing potential of the gases above the melt as well as any nitrates or polyvalent elements in the waste (Bickford, 1991). One of the primary tests for excessive amounts of organic compounds in the melter feed is determining the ratio of $\mathrm{Fe}^{2+}$ to $\mathrm{Fe}^{3+}$ or $\mathrm{Fe}^{2+}$ to total iron. Accurate control of the redox state can lead to better metal retention within the melt, a more durable final glass product, more efficient heat transfer within the melt, and a better Destruction and Removal Efficiency (DRE) of organic compounds in the feed.

Cesium is a semi-volatile metal. This is of concern at nuclear sites because it is primarily present as a radioactive isotope such as Cs-137. Therefore, it is imperative that Cs retention be maximized in any treatment process. Volatility of metal species is dependent on process temperature, so process temperatures must be minimized to facilitate retention of cesium in the glass.

\section{III.C.6. Vitrification Campaign Results}

Initially, the melter vessel was filled to approximately 6 inches with a glass composition made previously in the stirred melter. The melter and auxiliary temperature controllers were set to setpoints of $1070^{\circ} \mathrm{C}$ and $1045^{\circ} \mathrm{C}$, respectively. The oxygen sparger was then turned on at a rate of $1200 \mathrm{~mL} / \mathrm{min}$ at STP. The scrubber was filled with a known amount of tap water and turned on. The bubbler was allowed to fill with tap water to the level control tube. When the glass melt had reached the setpoint temperatures, the ion exchange resin/slurry feed was introduced into the melter. The feed was added to the melter at a rate of $51 \mathrm{~mL} / \mathrm{min}$. The feed tank level was maintained by adding resin and slurry to the tank in the same ratio as the initial amount during the run. The batch was fed to the melter for 20 hours or the equivalent of roughly 3.1 tank volumes throughput. During the course of the run, samples of feed, exit glass, bubbler tank solution, and scrubber solution were taken in order to approximate a cesium mass balance on the melter and to determine the effect of the resin feed on the redox state of the glass. Samples of the off-gas were also taken using a modified method 5 train and a multiple metals sampling train in order to characterize the off-gas with respect to any semi-volatile organic compounds present as products of incomplete combustion, volatile metals, and particulate matter. 
WSRC-TR-95-0412

Page 42 of 53

September 29, 1995

During the run there were no significant operational problems. A total amount of 25.87 $\mathrm{kg}$ of glass was poured from the melter during the campaign.

Glass samples were taken every 30 minutes during the test campaign. The composition of four of the samples was determined (Table III.7.). Since no cesium was present in the start-up glass frit, the temporal changes in cesium concentration is consistent with what would be expected in a continuous stirred tank (CSTR).

Table III.7.

Analysis of Exit Glass Samples Taken at Different Times

\begin{tabular}{ccccc}
\hline \hline wt\% oxide & 0 minutes & 627 minutes & 920 minutes & 1385 minutes \\
\hline $\mathrm{Cs}$ & 0.00 & 0.24 & 0.30 & 0.35 \\
$\mathrm{~K}$ & 2.43 & 2.70 & 2.76 & 2.76 \\
$\mathrm{Li}$ & 4.75 & 4.79 & 4.82 & 4.80 \\
$\mathrm{Na}$ & 6.69 & 6.69 & 6.73 & 6.76 \\
$\mathrm{Al}$ & 3.09 & 3.05 & 3.04 & 3.07 \\
$\mathrm{~B}$ & 7.90 & 7.75 & 7.76 & 7.80 \\
$\mathrm{Ca}$ & 1.70 & 1.24 & 1.23 & 1.24 \\
$\mathrm{Cr}$ & 0.19 & 0.17 & 0.17 & 0.17 \\
$\mathrm{Fe}$ & 12.00 & 12.25 & 12.50 & 12.57 \\
$\mathrm{Mg}$ & 1.56 & 1.53 & 1.56 & 1.56 \\
$\mathrm{Mn}$ & 2.64 & 2.74 & 2.80 & 2.80 \\
$\mathrm{Ni}$ & 1.15 & 1.18 & 1.20 & 1.21 \\
$\mathrm{Si}$ & 54.10 & 52.70 & 53.55 & 53.67 \\
Total & 98.19 & 97.01 & 98.38 & 98.73 \\
\hline
\end{tabular}

Note: The analysis results shown for 1385 minutes are the average of two analysis results.

A mass balance for cesium was determined based on glass analyses, analyses of off-gas deposits and analyses of scrubber solutions. Between 84.7 and 96 percent of the cesium that entered the melter system was accounted for in the exit glass stream and the off-gas treatment system. A cesium retention efficiency in the glass was calculated as between 82.3 and 93.2 percent. Between 2.4 and 2.8 percent of the cesium was found in the offgas treatment system.

Samples of the glass were taken periodically from the exiting glass stream and analyzed for the $\mathrm{Fe}(\mathrm{I}) / \mathrm{Fe}$ (total) ratio. The redox results indicated that the melt was never extremely reducing since none of the samples analyzed exceeded 0.3 for the $\mathrm{Fe}(\mathrm{II}) / \mathrm{Fe}$ (total) ratio. The average $\mathrm{Fe}(\mathrm{II}) / \mathrm{Fe}$ (total) ratio after approximately one hour of operating time was 0.176 . It was concluded that at a feed rate of 0.50 grams of dry resin per minute there would be no significant problems associated with an over reduced melt. 
WSRC-TR-95-0412

Page 43 of 53

September 29, 1995

\section{III.D. Rocky Flats Plant (RFP) Precipitate Sludge}

\section{III.D.1. Test Objectives}

The principal objectives of this melter campaign were to demonstrate the feasibility of vitrifying RFP precipitate sludge in a continuously operated stirred melter and to characterize the environmental impact of the vitrification process. The test program was aimed at obtaining information relating to: product quality, off-gas emissions characterization, material balances, and melter behavior and performance. A summary of the data relating to melter operation from this study is provided below.

III.D.2. Waste Composition

A description of the waste stream and the tested surrogate composition is discussed in section II.C.2. of this report.

III.D.3. Glass Formulation

A borosilicate glass with a low melting temperature of $\approx 1040^{\circ} \mathrm{C}$ was chosen for the glass formulation to be demonstrated in the Stir-Melter. The feed composition was based on a $65 \mathrm{wt} \%$ waste loading (on a dry oxide basis). Glass forming additives, on a dry oxide basis, consisted of $14 \mathrm{wt} \%$ borax and $21 \mathrm{wt} \%$ diatomaceous earth. The glass formulation was determined by SRTC based on a combination of crucible studies and glass formulation models (Cicero, 1994). In addition to the glass forming additives, activated carbon at $\mathbf{3} \mathrm{wt} \%$ was chosen as a feed additive to control the formation of sulfate salts. Crucible studies by Cicero and Andrews at SRTC found activated carbon addition at $3 \mathrm{wt}$ $\%$ to be sufficient to eliminate salt formation (Cicero, 1994).

III.D.4. Melter Operation

The Stir-Melter joule-heated, stirred melter has three main process control variables: melt temperature, feed rate, and impeller speed. These three variables were used to maximize the melt rate and throughput. The melter was operated under melt temperature-based power control. This control method varies the amount of current and voltage applied to the melt based on the temperature of the melt. In theory this allows a constant power to be applied. The melter was operated with the added constraint that full power applied to the melt was $80 \%$ of the overall power capability of the system.

\section{III.D.5. Process Challenges}

Three components of the sludge were of an unusual nature and were the focus of potential processing problems. Calcium sulfate, sodium nitrate, and iron oxide constituted $77.5 \mathrm{wt}$ $\%$ of the dry sludge and $50.38 \mathrm{wt} \%$ (dry basis) of the waste loading fed to the StirMelter. Vitrifying a waste with these components in such abundance had yet to be attempted. 
WSRC-TR-95-0412

Page 44 of 53

September 29, 1995

High calcium content typically places limitations on waste load processing due to the tendency for devitrification through the formation of calcium silicate species. The formation of crystals in the melter can hinder homogenization of the glass and, more importantly, discharge from the melter. Also, the presence of calcium sulfate introduces competing processes into the melt. Calcium sulfate is a stable compound that melts at temperatures $>1400^{\circ} \mathrm{C}$ and has a density that is significantly less than typical waste glasses. Calcium sulfate can react with alkali to produce additional alkali sulfates. Sulfates have a limited solubility in glass. It is therefore possible that the sulfate salts will melt, float on the molten surface, and hinder incorporation of the calcium into the glass due to the limited solubility of a stable sulfate salt.

Sodium nitrate poses process challenges in two areas: off-gas and glass processing. Sodium nitrate decomposes at $\approx 600^{\circ} \mathrm{C}$ to sodium oxide and nitrogen oxides (primarily $\mathrm{NO}, \mathrm{NO}_{2}$ ). $\mathrm{NO}_{\mathrm{x}}$ emissions are respiratory irritants and toxic in sufficient quantities. It is therefore necessary to monitor and treat $\mathrm{NO}_{\mathrm{X}}$ emissions as they are evolved. In terms of glass processing, it is possible for the sodium and sulfate within the feed to interact on the melt surface and form sodium sulfate. Sodium sulfate, like calcium sulfate, is a stable salt even at high melter temperatures. Sodium sulfate has many of the same characteristics of calcium sulfate and could hinder incorporation of sodium, a major glass component and fluxing agent, into the glass. The overall impact of sulfate salt formation on the demonstration could be the formation of a glass deficient in calcium and sodium with physical and chemical properties greatly different from the target glass composition.

Sulfate salt formation has occurred in crucible studies of this waste. Activated carbon, at a waste loading of $3 \mathrm{wt} \%$ (dry basis), was added to the feed material in an attempt to reduce the sulfate salts to gaseous $\mathrm{SO}_{2}$ which may be treated in the off-gas system. However, introduction of a strong reducing agent such as activated carbon could cause excessively reducing conditions in the glass melt. Since metals in their reduced states tend to be more volatile, an excess of activated carbon could prevent the incorporation of hazardous metals and radionuclides into the glass matrix.

Melter integrity in the Stir-Melter campaign is of vital importance. The Inconel ${ }^{\mathrm{TM}} 690$ that comprises the melter vessel and the impeller has excellent corrosion properties under moderate oxidizing conditions. However, under reducing conditions, Inconel ${ }^{\mathrm{TM}} 690$ is susceptible to severe corrosion and failure from aggressive chemical attack, especially sulfidization. With the addition of activated carbon, the potential to operate the melter under reducing conditions is extremely high. In an attempt to limit the reducing conditions within the melt, an on-line redox probe has been installed on the melter to aid in tracking the redox state of the glass. 
WSRC-TR-95-0412

Page 45 of 53

September 29, 1995

III.D.6. RFP Vitrification Campaign Results

The RFP vitrification campaign never progressed past the operational parameter studies due to catastrophic impeller failure. Following the failures, two impeller shafts and three samples retrieved from the bottom of the melter were analyzed. One melter shaft was Inconel ${ }^{\mathrm{TM}} 690$ while the other was Inconel ${ }^{\mathrm{TM}} 601$ (from of an impeller assembly repaired at Clemson). The InconelTM 690 shaft remained from the first impeller failure while the InconelTM 601 shaft remained following the second failure. The tips of the impeller shafts were slightly rounded. A dendritic microstructure was observed at the tip of the Inconel ${ }^{\mathrm{TM}} 690$ shaft indicative of melting of the Inconel ${ }^{\mathrm{TM}}$ material. This result is not surprising since after the failure of the impeller blades and ring assembly, current flow was restricted through a significantly reduced area causing excessive current densities. The examined end of the Inconel ${ }^{\mathrm{TM}} 601$ shaft revealed that the impeller assembly was likely welded to the shaft and failure occurred in the weld area.

The three samples from the bottom of the melter included: an agglomeration of spherical metal "globs", an apparent tip section of a shaft (likely from the InconelTM 601 assembly), and the outer ring of an impeller. The spherical metal "globs" were obviously the result of melting of the Inconel ${ }^{\mathrm{TM}}$ alloy. The spherical nature of the agglomerations and dendritic structure is indicative of a solidification structure. Some very interesting observations were made when examining the failed ring assembly. Spherical "globs" were observed adhering to the ring likely at the locations of the welded impeller blades. Examination of this region indicated that melting of the blade was likely occurring at this location but the ring remained relatively intact with little change in the microstructure. This behavior was likely caused by high current densities at the tips of the blades (moreover, at the "corner" connections to the ring) causing localized hot spots and subsequent melting of the InconelTM 690 . The melting in the weld area could also have been due to the use of a lower melting alloy filler metal in the welds.

During operation of the stirred melter, temperatures are monitored by thermocouples on the exterior of the melt vessel wall or thermocouples submersed into the melt. Due to the high current densities in the electrode it is possible that localized temperatures on the electrodes are much higher than the monitored temperatures. During these failures, it is certain that some portions of the failed impeller separated first, resulting in higher current flux in the remaining portions. It is possible that the initial damage may have been caused by melting or corrosion or a combination of both. In any event, the initial damage to the electrode reduces the area of the impeller causing higher current densities in the impeller. Melting of the impeller appears to be the end result of this process as "globs" and pellets of Inconel ${ }^{\mathrm{TM}}$ alloy are observed in the bottom of the melt vessel. Other contributing factors may be related to the relative size of the system. Due to the small melter size, there is uncertainty in the fluid flow in the system. Increased temperatures in the impeller 
WSRC-TR-95-0412

Page 46 of 53

September 29, 1995

may result from inadequate mixing adjacent to the impeller resulting in localized hot spots. Additionally, high glass resistivities may exaggerate the above scenarios.

A few processing problems were observed during operational parameter studies. As in the EV-16 campaign, the melt rate was slow. Foaming and sulfate salt formation were of even greater intensity than in the EV-16. This appeared to be the result of quicker batch incorporation due to the mixing action from the impeller and a higher waste loading. Foam layers within the vessel were at times 8 to 10 inches in depth. The impeller agitation does not allow the batch to degas before it is pulled below the surface of the melt. The result is an extremely foamy glass melt. The presence of gas within the melt increases the resistance of the glass to current flow. This causes higher loads to be applied to the power supply which in turn can lead to excessive wear on the electrodes from higher current densities. Since the intensity of the foam was observed to be directly related to the power input to the melt, a deteriorating cycle began as soon as foam formation occurred.

The presence of a foam layer also affected the drain procedure. Glass draining is unsteady and intermittent with a foamy glass. The present Stir-Melter overflow drain design actually acted as a fining chamber, allowing glass to degas before draining. Unfortunately, this design would not allow glass to drain until the glass in the entire overflow chamber had equilibrated. This prevented continuous draining of the melter.

Sulfate salt formation was significantly greater than in the EV-16, on a qualitative basis. A molten salt layer formed and floated on the surface of the glass melt. The molten salt layer slowly volatilized or was entrained with particulate matter into the off-gas system. Although no off-gas piping blockages occurred during the short operational parameter studies, a layer of sulfate salts, sometimes 4-5 mm thick, did condense on the-off-gas riser immediately above the melter. It is conceivable that blockages would occur during long operational campaigns.

Redox conditions of the melt during the operational parameter studies are unknown due to difficulties with the redox probe. Visual inspection of the melter vessel and impeller after the operational parameter studies showed no noticeable wear or attack. The visual inspection were performed before the catastrophic impeller failures.

\section{III.E. Lessons Learned}

A summary of the operation and performance of the stirred melter during the vitrification campaigns is shown in Table III.8. 
WSRC-TR-95-0412

Page 47 of 53

September 29, 1995

Table III.8. Stir-Melter Operation Summary

\begin{tabular}{|c|c|c|c|c|}
\hline & & $\underline{\text { Melter Ca }}$ & mpaign & \\
\hline & M-Area Sludge & WETF Sludge & $\begin{array}{l}\text { Ion-exchange } \\
\text { Resin }\end{array}$ & $\begin{array}{l}\text { Rocky Flats } \\
\text { Precipitate sludge }\end{array}$ \\
\hline Glass Type & Borosilicate & $\begin{array}{l}\text { Borosilicate } \\
\text { Alkali-Lime-Silica }\end{array}$ & Borosilicate & Borosilicate \\
\hline Waste Loading & $\begin{array}{l}80 \text { wt } \% \text {, } \\
85 \text { wt } \%\end{array}$ & $\begin{array}{l}\text { BS - } 45 w t \% \\
\text { ALS - } \approx 35 w t \%\end{array}$ & 4.9 wt $\%$ & $65 \mathrm{wt} \%$ \\
\hline Feeding & Dry & Slurry & Slurry & Slurry \\
\hline Melt Cap & Cold Top & Hot Top & Hot Top & Hot Top \\
\hline $\begin{array}{l}\text { Setpoint and/or } \\
\text { Melter Power }\end{array}$ & $\begin{array}{l}1050^{\circ} \mathrm{C} \\
7 \mathrm{~kW}\end{array}$ & $\begin{array}{l}\text { BS }-1050^{\circ} \mathrm{C} \\
\text { ALS- } 1070^{\circ} \mathrm{C}\end{array}$ & $1070^{\circ} \mathrm{C}$ & $\begin{array}{l}1040^{\circ} \mathrm{C} \\
8 \mathrm{~kW}\end{array}$ \\
\hline $\begin{array}{l}\text { Process } \\
\text { Challenges }\end{array}$ & $\begin{array}{l}\text { Dry feeding } \\
\text { Ni incorporation }\end{array}$ & $\begin{array}{l}\text { High temp. glass } \\
\text { High Ca content } \\
\text { Organic species }\end{array}$ & $\begin{array}{l}\text { High organics } \\
\text { Cs volatility }\end{array}$ & $\begin{array}{l}\text { High Ca content } \\
\text { High sulfate conc } \\
\text { High nitrate conc }\end{array}$ \\
\hline $\begin{array}{l}\text { Process } \\
\text { Difficulties }\end{array}$ & $\begin{array}{l}\text { Feed entrainment } \\
\text { Off-gas pluggage }\end{array}$ & $\begin{array}{l}\text { Devitrification } \\
\text { Off-gas pluggage } \\
\text { Sulfide formation } \\
\text { Reducing melt } \\
\text { Impeller damage }\end{array}$ & No major & $\begin{array}{l}\text { Impeller failure } \\
\text { Foaming } \\
\text { Sulfate salt layer }\end{array}$ \\
\hline
\end{tabular}


The most significant problem encountered during the Stir-Melter campaigns and previous Stir-Melter scoping trials (Jenkins, 1993) was impeller degradation. At times the impeller was exposed to excessive temperatures that resulted in melting of the Inconei ${ }^{\mathrm{TM}} 690$ and rapid, catastrophic impeller failure. It is difficult to identify one root cause for this problem; instead, there are likely several contributing factors. The first impeller failure (Jenkins, 1993) was likely caused by faulty temperature control resulting in operation of the melter at approximately $1230^{\circ} \mathrm{C}$ or higher (more than $150^{\circ} \mathrm{C}$ higher than recommended operating temperature). Subsequent failures observed in the WETF campaign and at the start of the Rocky Flats trial indicate other contributing factors exist. In these tests, the monitored temperatures were in the recommended operating range $\left(<1070^{\circ} \mathrm{C}\right)$. It must be noted that temperatures are monitored by thermocouples on the exterior of the melt vessel wall or thermocouples submersed into the melt. Due to the high current densities in the electrode, it is possible that localized temperatures on the electrodes are much higher than the monitored temperatures. During these failures, it is certain that some portions of the failed impeller separated first, resulting in higher current flux in the remaining portions. It is possible that the initial damage may have been caused by corrosion or melting or a combination of both. In any event, the initial damage to the electrode reduces the area of the impeller causing higher current densities in the impeller. The melting of the impeller appears to be the result of this process as "globs" and pellets of Inconel ${ }^{\mathrm{TM}}$ alloy are observed in the bottom of the melt vessel. Other contributing factors may be related to the relative size of the system. Due to the small melter size, there is uncertainty in fluid flow and mixing in the system. It is possible that inadequate mixing occurred adjacent to the impeller resulting in localized hot spots. Additionally, high glass resistivities may exaggerate the above scenarios.

Improved temperature measurement in the system may help alleviate this problem by ensuring that true melt temperatures are better known and that the melt temperature remains in a "safe" region. Development and use of lower melting temperature glass formulations would also be beneficial to operation of the melter. However, this approach may be limited due to durability requirements of the waste form. The avoidance or minimization of corrosive species in the glasses would also likely minimize this behavior (see below). Finally, knowledge of the resistivities of the glass compositions run in the melter would be helpful.

Devitrification of the glasses caused problems similar to those observed in the EnVitco melter. Clogging of the drain tube occurred in the WETE runs. This again points out limitations in $\mathrm{CaO}$ concentration in these waste glasses and the need for better characterization of the glass formulations. Manual clearing of the drain tube and heating the tube with a torch was necessary to facilitate pouring of the glass. During the test runs several modifications were made to the drain tube with relatively little success. The 
WSRC-TR-95-0412

Page 49 of 53

September 29, 1995

relatively small vessel size may result in too slow throughput, consequently impeding glass flow from the melter.

Pluggage of the off-gas system occurred in the M-area run due to dry feeding and entrainment of the fine particle sized batch. Clogging of the off-gas system was also observed in the borosilicate WETF run.

Extreme reducing conditions were also observed during the WETF runs. This resulted in the formation of metal sulfides which were recovered as metal pellets in the bottom of the melter. Although, the formation of the pellets appeared to have no detrimental effects to the operation of the melter, the potential to cause corrosion of the impeller or interference with Joule heating must be considered.

\section{Conclusions}

The following conclusions were drawn from the melter studies at the DOE/Industrial Center for Vitrification Research at Clemson University:

- The quality of glass made in the melters was generally excellent. In essentially all cases, glass durabilities (measured by PCT) were much better than the Environmental Assessment (EA) glass and leachabilities (measured by TCLP) were lower than Land Disposal Requirements (LDR).

- A few processing difficulties were identified with the EnVitco melter, including:

- Devitrification of the melt impeding glass pouring (especially evident with high calcium compositions).

- Corrosion of molybdenum electrodes by alloying with reduced melt metals.

- Significant corrosion of flux block refractory when operating at high temperatures.

- Limits in melt rate of feed which prevented continuous feeding and pouring of melter.

- The lessons learned in the operation of the Stir-Melter included:

- Rapid degradation of impeller likely due to localized melting of Inconel ${ }^{\mathrm{TM}} 690$.

- Devitrification of glass melt interfering with pouring of glass:

- Pluggage of the off-gas system.

- Metal species precipitating from melt under extreme reducing conditions. 


\section{v. Current Activities}

A campaign was just completed in the EnVitco melter with a Los Alamos Laboratory lowlevel waste sludge surrogate. The results of this run will be examined and added to the "lessons learned" database. A run with this surrogate sludge is also planned for the StirMelter in early FY' 96 . Also in FY '96, a mercury contaminated waste, hazardous soil waste, and an organic surrogate waste stream will be examined in the EnVitco melter. Knowledge obtained from previous trials will be used extensively in the FY' 96 efforts to promote more efficient operation of the melters.

Additional FY ' 96 activities are focused on demonstrating controls and corrections for the operating difficulties discussed above. A synopsis of these efforts follows:

Devitrification: An abbreviated Time-Temperature-Transformation (TTT) test will be developed which can be used in the field to determine the sensitivity of waste glass formulations to devitrification. This will be compared to new EnVitco test runs with variable feed compositions to determine maximum melt rate and waste loading for high calcium and high aluminum feed that is compatible with this melter.

Molybdenum electrode corrosion: Ultrasonic length measurement of electrodes as a means of monitoring electrode wear and wear rates without breaking radioactive contamination barriers will be examined.

Flux block refractory corrosion: Thermocouple located near the electrodes will be tested as a means of monitoring refractory wear and of avoiding "hot spots" near the electrodes. This will improve operating life and safety by reducing the risk of unexpected refractory loss.

Melt rate limits: Dry and damp compounded feed from sludges will be investigated as a means of increasing melt rates. Successful demonstration of these techniques could double the throughput of the TVS and similar melters, such as the Duratek melter being developed for treatment of the SRS M-area plating line sludge.

Stir-Melter impeller degradation: Alternative impeller designs will be tested which are less likely to result in a "dead space" adjacent to the impeller. The new designs will feature higher surface area to better dissipate heat from the impeller.

Testing in larger Stir-Melter: Vitrification testing on "a to be determined" surrogate waste stream will be performed in a larger Stir-Melter unit at the equipment manufacturers' headquarters. Melt processing and glass pouring performance in this larger unit is 
expected to be much improved over the smaller Clemson melter. Operation of the two melter systems will be compared in this effort.

Redox proves: Redox probes for real time/on-line monitoring of the redox conditions of the glass melt will be tested.

The Transportable Vitrification System (TVS) will be tested and readied for actual radiological use in FY' '96. The database obtained from the Clemson studies will be applied to operation of the TVS melter wherever possible. This will hopefully aid in the smooth start-up of the TVS and transition into radiological operation. 
WSRC-TR-95-0412

September 29, 1995

Page 52 of 53

\section{References}

Andrews, M. K. and C. A. Cicero (1993), "ORNL WETF Simulated Sludge Crucible Studies", WSRC-TR-93-647, Westinghouse Savannah River Company, Aiken, SC.

Bennert, D. M. (1995), M.S. Thesis to be published, Clemson University, Clemson, SC.

Bennert, D. M., T. J. Overcamp, D. F. Bickford, C. M. Jantzen, and C. A. Cicero (1994), "Demonstration of Vitrification of Surrogate F006 Wastewater Treatment Sludges", Environmental and Waste Management Issues in the Ceramic Industry II Symposium Proceedings, American Ceramic Society, Indianapolis, IN.

Bibler, J. P. and R. M. Wallace, "Testing a New Cesium-Specific Ion Exchange Resin for Decontamination of Alkaline High-Activity Waste", Proceedings of Waste Management '90, American Nuclear Society, Tucson, AZ.

Bickford, D. F., and R. B. Diemer (1986), "Redox Control of Electric Melters with Complex Feed Compositions: I. Analytical Methods and Models", Journal of NonCrystalline Solids, 84, pp. 276-284.

Bickford, D. F. and A. S. Choi (1991), "Control of High Level Radioactive Waste-Glass Melters - Part 5: Modeling of Complex Redox Effects", Proceedings of the Fifth International Symposium on Ceramics in Nuclear and Hazardous Waste Management, American Ceramic Society, Cincinnati, $\mathrm{OH}$.

Cicero, C. A. and M. K. Andrews (1994), "Simulated RFP Precipitate Sludge Crucible Studies (U)", WSRC-TR-94-00107, Westinghouse Savannah River Company, Aiken, SC.

Funk, J. E. and D. R. Dinger (1994), Predictive Process Control of Crowded Particulate Suspension Applied to Ceramic Manufacturing, Kluwer Academic Publishers, Hingham, MA, Chapter 24, pp. 351-368.

Hewlett, K. J. (1994), "Vitrification Demonstration of West End Treatment Facility Mixed Waste Sludge", M.S. Thesis, Clemson University, Clemson, SC.

Jantzen, C. M., N. D. Hutson, T. M. Gilliam, A. Bleier, and R. D. Spence (1995), "Vitrification Treatability Studies of Actual Waste Water Treatment Sludges", Proceedings of Waste Management '95, American Nuclear Society, Tucson, AZ. 
Jantzen, C. M., J. B. Pickett, and W. G. Ramsey (1993), "Reactive Additive Stabilization Process (RASP) for Hazardous and Mixed Waste Vitrification", Proceedings of the Second International Mixed Waste Symposium, Baltimore, MD.

Jenkins, C. F. (1993), "Clemson Stirred Melter - Impeller/Electrode Failure (U)", SRTMTS-935150, Westinghouse Savannah River Company, Aiken, SC.

Richards, R. S. and V. Jain (1993), "Rapid Stir Melting of Simulated West Valley High Level Waste", Environmental and Waste Management Issues in the Ceramic Industry Symposium Proceedings, American Ceramic Society, Cincinnati, $\mathrm{OH}$.

Sargent, T. N. (1994), "Vitrification of Cesium-Contaminated Organic Ion Exchange Resin", M.S. Thesis, Clemson University, Clemson, SC. 
Melter Performance During Surrogate Vitrification Campaigns at the DOE/Industrial Center for Vitrification Research at Clemson University - (U)

James C. Marra

Westinghouse Savannah River Company

Thomas J. Overcamp

Clemson University - Environmental Systems Engineering Department

Distribution:

E. W. Holtzscheiter, 773-A

E. F. Duhn, 773-A

M. J. Plodinec, 773-43A

D. A. Crowley, 773-23A

J. R. Harbour, 773-43A

L. F. Landon, 704-1T

C. T. Randall, 704-T

N. E. Bibler, 773-A

D. F. Bickford, 773-43A

R. A. Jacobs, 704-T

G. S. Bumgarner, 773-41A

C. A. Cicero, 773-41A

B. D. Helton, 773-41A

D. T. Herman, 773-41A

K. J. Imrich, 773-A

C. M. Jantzen, 773-A

A. L. Kielpinski, 773-41A

R. F. Schumacher, 773-41A

J. C. Whitehouse, 773-23A

W. G. Ramsey, 704-1T

M. E. Smith, 773-23A

M. K. Andrews, 773-A

J. C. Marek, 704-T

H. F. Sturm, 773-A

STI, 703-43A (4)

T. J. Overcamp, Clemson, ESE

D. L. Erich, Clemson, ESE

R. A. Wilson, Clemson, ESE 